\title{
Thermal and Mechanical Analysis of a 72/48 Switched Reluctance Motor for Low-Speed Direct-Drive Mining Applications
}

\author{
Esmail Elhomdy ${ }^{1,2}$, Zheng Liu ${ }^{1}$ and Guofeng $\mathrm{Li}^{1, *}$ \\ 1 School of Electrical Engineering, Dalian University of Technology, Dalian 116023, China \\ 2 Faculty of Engineering, Blue Nile University, Blue Nile State 26613, Sudan \\ * Correspondence: guofenli@dlut.edu.cn; Tel.: +86-138-8962-6136
}

Received: 2 June 2019; Accepted: 2 July 2019; Published: 5 July 2019

\begin{abstract}
In the process of electric motor design, it is essential to predict and provide an accurate thermal and mechanical model. The aim of this research is to improve the thermal and mechanical performance - which is implemented into a $72 / 48$ switched reluctance motor (SRM) with $75 \mathrm{~kW}$-of a low-speed direct-drive mining system (pulverizer). Thermal analysis of the SRM requires a deep understanding of the coolant behavior and the thermal mechanism in the motor. Computational fluid dynamics (CFD) based finite element analysis (FEA) was carried out in order to precisely visualize and estimate fluid state and temperature distribution inside the motor. Several different coolant configurations were carried out, with the purpose of determining an appropriate one for uniform temperature distribution in the SRM. The natural frequencies are presented with the developed finite element mechanical, structural model. To adapt in the mining application, the cooling jacket configurations with 17 channels and the shaft with spoke was found to be optimal for the SRM, which may raise the natural frequency and reduce the weight and temperature of the motor. The simulations results showed a good agreement with experimental results regarding temperature distribution within the motor.
\end{abstract}

Keywords: computational fluid dynamics; finite element method; mechanical analysis; switched reluctance motor; 3D thermal model

\section{Introduction}

To optimize the design of electrical machines in mining applications, it has become fundamental to elevate out mechanical and thermal analysis along with electromagnetic analysis. Application of a direct drive system has become an irresistible trend in the last decade as the knowledge of energy consumption optimization increased. The switched reluctance motor (SRM) used for Pulverizing in mining applications is usually required to be with high-torque and low-speed, which will typically cause the high-temperature to rise and unpredictable vibration [1], which may create the conditions for catastrophic results and human casualties, if they are not taken account of. The SRM has no rare earth material as permanent magnets. Consequently, higher currents are required in order to produce high torque. Moreover, these higher currents cause a large amount of losses in the winding. In addition, the magnetically saturated operation of the SRM also leads to higher magnetic losses, which will typically cause an increase of the temperature of the SRM. This temperature rise may increment resistance and decrease both efficiency and the insulation lifespan of the motor winding [2-7]. Therefore, predicting the temperature filed precisely and hotspot positions inside the SRM is needed. In order to keep the operating temperature of the SRM within the permitted limit, a cooling system should be developed [8-14]. Moreover, mechanical characteristics, including acoustic noise and vibration, 
are significant factors that impact on the operating reliability and service life of the SRM. They are induced by the electromagnetic force within the air-gap between the stator and the rotor. Mechanical vibration is one of the major mechanical faults to cause a breakdown of electric machines. It is thus exceptionally significant to evaluate the mechanical vibration performance of the SRM to escape mechanical failures [15-18].

Hence, many researchers have investigated thermal analysis, vibration and acoustic noise analysis of the SRM $[12,15,19]$. In References [20-22] the lumped parameter thermal network (LPTN) analysis model and the finite element method (FEM) were established to compute the temperature of the SRM. LPTN has the advantages of fast computation speed even for thermal transients. However, the accuracy of LPTN is limited by the appropriateness of how the thermal resistance components are set [20]. Convective heat transfer is still the most complex issue which needs a better understanding of fluid flow within the motor [23]. The coupled thermal analysis is made through CFD and FEM gives enough valuable results on the motor temperature rise. Thus, the boundary condition of the equivalent thermal model can be obtained according to the CFD theory $[24,25]$. The radial force between rotor and stator is one of the significant sources of the vibration in the SRM. The study of vibration can be basically partitioned into two categories of time and frequency domain techniques [26]. In Reference [27] five approaches were employed to determine motor natural frequencies. The calculation of motor natural frequencies is necessary for the vibration of SRM [17]. Using a simulation environment ANSYS-Workbench, the acoustic noise and vibration created by the transient electromagnetic forces on the stator of an electric machine were presented previously [28]. However, the water jacket (WJ) optimization design has not been intensely studied and requires further research [2]. High temperatures caution the designer to minimize the losses, modify the cooling type, or optimize the machine. SRM thermal performance is generally influenced by two components. First is the sum of heat sources inside the SRM produced from losses. The second is how well the produced heat can be dissipated out from the SRM.

In this paper, the losses of the SRM are evaluated utilizing the FEM to assist thermal analysis. The water cooling system is a very efficient method of transferring heat away from the $75 \mathrm{~kW}$ SRM for a high-torque low-speed on mining applications in harsh conditions. Meanwhile, the WJ of SRM not only undertakes the responsibility of heat dissipation but also has benefits of the structure of mechanical protection. Commonly in SRM, both the stator and the rotor employ the doubly salient teeth structure, leading to electromagnetic forces in the air gap when the phase current is excited. The rotor and stator are under electromagnetic forces that can change the air gap between them. The change of the gap affects the electromagnetic fields between a rotor and a stator; so, the calculation of vibration amplitudes is important and considered in this paper. So, it is essential to anticipate the natural frequencies in order to design a quiet SRM or to escape working the motor near the resonant frequency during drive operation [15-19].

For the goal of the reliable and stable operation of the SRM in a mining application, the thermal and mechanical design of the WJ of the SRM is discussed in this paper. The temperature rise in the SRM is analyzed in this paper. Three-dimensional CFD was established using ANSYS-Workbench to determine the temperature of each point of the SRM, which helps to find the hot spot. The motor temperature distribution under rated load was determined. Moreover, the natural frequencies of the prototype were computed using 3D finite element analysis (FEA). The tangential and radial forces of the air gap flux densities were calculated. Then, the radial forces were applied to the 72/48 SRM for a harmonic analysis using 3D FEA so that the total deformation of the machine can be visualized and analyzed. The temperature rise experiment was performed on a motor prototype.

\section{3D Thermal Model}

The thermal distribution of the SRM provides knowledge to the designer. The SRM considered in this paper has an outer water-cooled peripheral casing structure. Water-cooled, the SRM for mining applications utilizes a closed structure. When the motor is working most of the heat delivered within 
the stator and rotor is passed to the housing through heat conduction, then the water flowing in the waterways dissipates the heat of the housing. The following presumptions are carried out to explain the model:

1. The insulating material completely covers windings;

2. The stator and the rotor iron losses remain constant with uniform heat generation;

3. Thermal conductivities of motor materials are isotropic.

Established on these presumptions, the structure of the 72/48 SRM considered in this paper is shown in Figure 1. The properties of isotropic material for each motor part are given in Table 1. The list of the geometrical dimensions is described in Table 2.

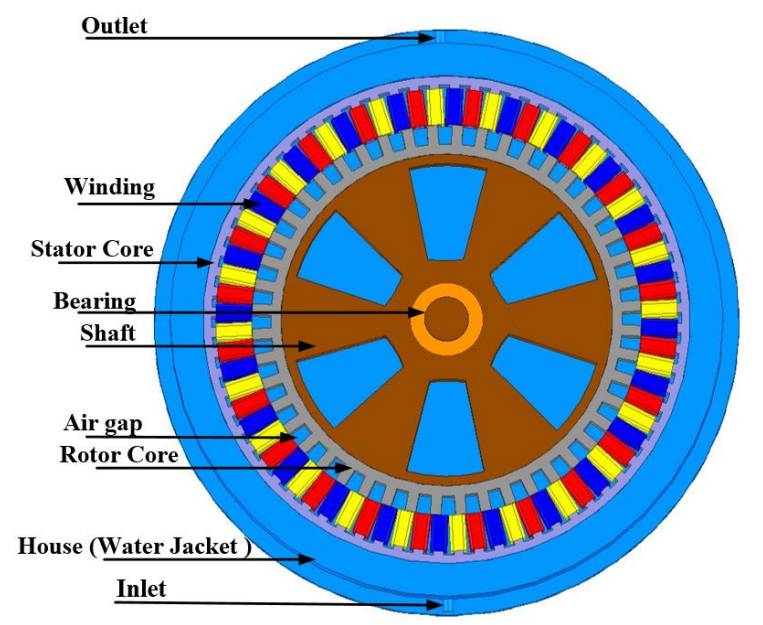

Figure 1. The structure view of the $72 / 48$ switched reluctance motor (SRM).

Table 1. Material properties of motor parts used in the simulations.

\begin{tabular}{lllllll}
\hline Components & Materials & $\begin{array}{l}\text { Density } \\
{\left[\mathbf{k g} / \mathbf{m}^{3}\right]}\end{array}$ & $\begin{array}{l}\text { Specific } \\
\text { Heat } \\
{\left[\mathbf{J} / \mathbf{k g} /{ }^{\circ} \mathbf{C}\right]}\end{array}$ & $\begin{array}{l}\text { Thermal } \\
\text { Conductivity } \\
{\left[\mathbf{W} / \mathbf{m} \cdot{ }^{\circ} \mathbf{C}\right]}\end{array}$ & $\begin{array}{l}\text { Young's } \\
\text { Modulus } \\
{[\mathbf{G P a}]}\end{array}$ & $\begin{array}{l}\text { Poisson's } \\
\text { Ratio }\end{array}$ \\
\hline Cover and Chassis & Aluminium alloy & 2790 & 833 & 168 & 69 & 0.33 \\
Stator/Rotor core & M19-29gauge steel & 7800 & 460 & 28 & 200 & 0.29 \\
Winding & Copper ( Pure) & 8933 & 385 & 401 & 116 & 0.35 \\
Insulating layer & Composite material & 1400 & 1000 & 0.21 & 3.5 & 0.3 \\
\hline
\end{tabular}

Table 2. The geometrical dimensions of the 72/48 SRM.

\begin{tabular}{llll}
\hline Parameter & Value & Parameter & Value \\
\hline Number of stator poles & 72 & Stack length [mm] & 340 \\
Number of rotor poles & 48 & Air gap length [mm] & 1 \\
Stator out diameter [mm] & 1000 & Rotor out diameter [mm] & 798 \\
Stator pole arc angle [deg] & 2.85 & Rotor pole arc angle [deg] & 3.15 \\
Stator pole width [mm] & 19.89 & Rotor pole width [mm] & 21.93 \\
Stator yoke thickness [mm] & 18 & Rotor yoke thickness [mm] & 20 \\
Stator slot depth [mm] & 82 & Rotor slot depth [mm] & 39 \\
Number of turns per pole [Turns] & 15 & Shaft diameter [mm] & 680 \\
\hline
\end{tabular}

Thermal studies of electric motors hold great significance as all of the materials employed are sensitive to heat. There are three methods by which heat can transfer: conduction, convection and radiation. Heat transfer by conduction is heat transferring through direct contact of materials, whereas heat transfer by convection is heat transferred by a fluid or gas. Heat transfer by radiation is when heat energy travels in actual waves. For isotropic media, the steady-state heat transfer governing equations and its boundary conditions can be presented as [15]: 


$$
k_{x x} \frac{\partial^{2} T}{\partial x^{2}}+k_{y y} \frac{\partial^{2} T}{\partial y^{2}}+k_{z z} \frac{\partial^{2} T}{\partial z^{2}}+h_{c v}\left(T-T_{a m b}\right)=Q,
$$

where $k$ is thermal conductivity $\left[\mathrm{W} / \mathrm{m} \cdot{ }^{\circ} \mathrm{C}\right], T_{a m b}$ and $T$ are ambient and unknown temperature $\left[{ }^{\circ} \mathrm{C}\right]$, $Q$ is the heat source $\left[\mathrm{W} / \mathrm{m}^{3}\right]$, and $h_{c v}$ is heat transfer coefficient $\left[\mathrm{W} / \mathrm{m}^{2} \cdot{ }^{\circ} \mathrm{C}\right]$.

To estimate the temperature distribution, the heat transfer coefficient and the total losses in the SRM are required inputs. The heat sources leading to the temperature rise of the motor come from all losses of the motor. These losses consist of the copper, core, and mechanical loss. Heat transfer convection helps the motor to be cool.

\subsection{Investigation of Losses (Heat Sources)}

Understanding the power losses associated with an electrical machine, their behavior and distribution are of paramount importance when evaluating machine performance and thermal distribution. The losses in electrical machines can be classified by the spatial distribution of heat sources. The calculations of the copper, core, and mechanical loss for SRM are presented in References [29-31]. The specific core losses $P_{F e}$ in $\left[\mathrm{W} / \mathrm{m}^{3}\right]$ can be expressed by the theory of the Bertotti equation [31]. The core loss is distributed into three items:

$$
P_{F e}=P_{h}+P_{e}+P_{e x}=k_{h} f B^{\alpha}+\frac{\sigma(\pi d)^{2}}{6 \rho} f^{2} B^{2}+k_{e x} f^{1.5} B^{1.5}
$$

where $P_{h}, P_{e}$ and $P_{e x}$ are hysteresis loss, eddy current loss and excess loss, respectively. The manufacturer of the magnetic sheets provides the value of iron loss in $[\mathrm{W} / \mathrm{kg}]$ for given values of magnetic flux density $(B)$ and frequency $(f)$. Based on curve fitting techniques, the loss coefficients $\left(k_{h}, \alpha\right.$ and $\left.k_{e x}\right)$ can be identified. These coefficients that are used to compute iron losses are described in Table 3 for ferromagnetic material M19-29 gauge steel. Moreover, the B-H curve and the measured manufacturer's core loss curves of M19-29 gauge steel are shown in Figure 2.

The ANSYS-Maxwell package was utilised to develop a loss model for the prediction of different components of the 72/48 SRM. To obtain the electromagnetic characteristics of the SRM, 2D FEM is developed. It evaluates the core losses in the SRM fed by an asymmetrical half-bridge power converter circuit and control circuit, which is modelled in SIMPLORER as presented previously [1]. The converter is powered by a $510 \mathrm{Vdc}$ power supply. The current chopper control of phase $\mathrm{A}$ is performed with a turn-on and turn-off angle of $3.87^{\circ}$ and $6.37^{\circ}$, respectively, the sequence of phase $B$ and $C$ has been reported previously [1]. The average of the electromagnetic torque is $7.28 \mathrm{kNm}$ obtained at DC current $174 \mathrm{~A}$. The core loss distribution in the stator and rotor at rotor positions $6.28^{\circ}$, rated speed $105 \mathrm{rpm}$ and rated load can be seen in Figure 3a. The copper losses were specified as functions of stator Dc current with winding resistance per phase $(0.217 \Omega)$, as shown in Figure $3 b$. In summary, the main losses in different portions of the 72/48 SRM are listed in Table 4.

Table 3. Material coefficients for ferromagnetic M19-29gauge steel.

\begin{tabular}{lll}
\hline Description & Value & Unit \\
\hline Hysteresis coefficient, $k_{h}$ & 165.36 & {$\left[\mathrm{Ws} / \mathrm{T}^{2} \mathrm{~m}^{3}\right]$} \\
Electric conductivity, $\sigma$ & $1.96 \times 10^{6}$ & {$[\mathrm{~S} / \mathrm{m}]$} \\
Lamination thickness, $d$ & $0.35 \times 10^{-3}$ & {$[\mathrm{~m}]$} \\
Excess loss coefficient, $k_{e x}$ & 0.517 & {$\left[\mathrm{~W} / \mathrm{T}^{1.5} \mathrm{~s}^{-1.5} \mathrm{~m}^{3}\right]$} \\
Mass density, $\rho$ & 7800 & {$\left[\mathrm{~kg} / \mathrm{m}^{3}\right]$} \\
\hline
\end{tabular}




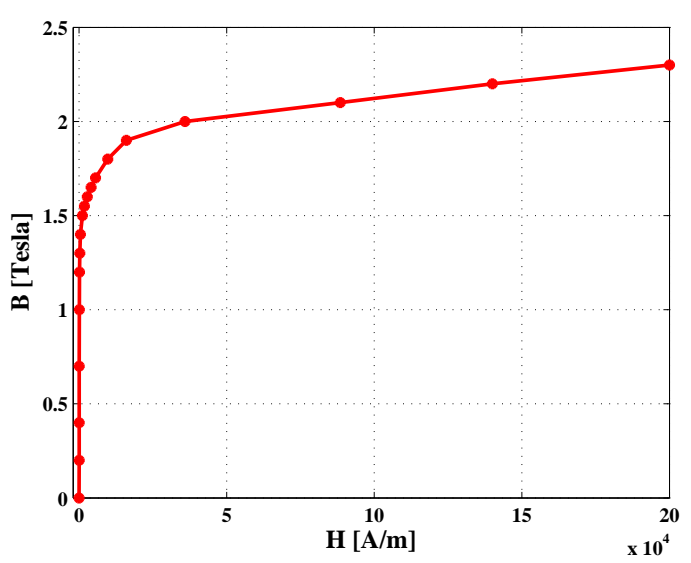

(a)

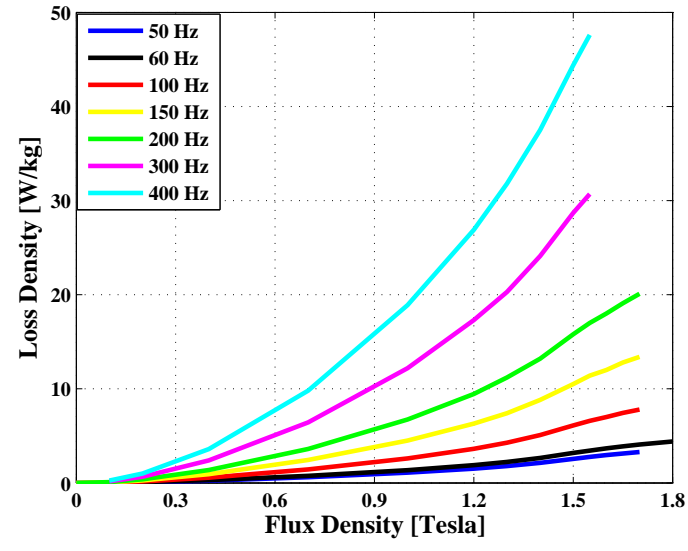

(b)

Figure 2. The magnetic properties of M19-29gauge. (a) the B-H curve, (b) the core loss curves.

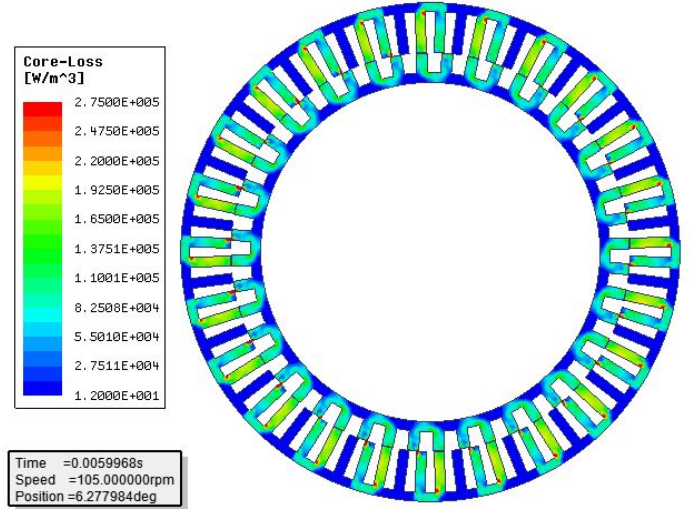

(a)

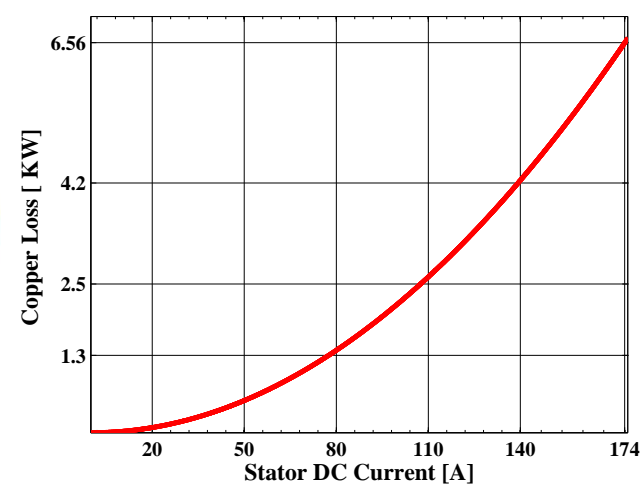

(b)

Figure 3. The loss of the SRM. (a) The density of core loss at $105 \mathrm{rpm}$ and rated load; (b) The copper loss versus stator DC current.

Table 4. The losses and weight in different portions of the 72/48 SRM.

\begin{tabular}{lll}
\hline Portions & Values of losses [W] & Weight $[\mathbf{k g}]$ \\
\hline Windings & 6560 & 199.6 \\
Stator & 1445 & 436.6 \\
Rotor & 650 & 214.6 \\
The Total & 8655 & 850.8 \\
\hline
\end{tabular}

\subsection{Heat Transfer Coefficient Boundary Conditions}

In References $[6,15,32,33]$, the natural and force convection based on the dimensionless analysis of empirical heat transfer correlations were predicted using Equations (3) and (4), respectively.

$$
\begin{gathered}
N u=a(G r P r)^{b}, \\
N u=a(\operatorname{Re})^{b}(\operatorname{Pr})^{c},
\end{gathered}
$$

where $N u, G r, P r$ and $R e$ are referred to Nusselt, Grashof, Prandt and Reynolds number respectively. The heat transfer coefficient $\left(h_{c v}\right)$ of the boundary conditions is presented in Equation (1); however, we applied the following boundary conditions for the SRM model. All coefficients $\lambda_{e f}, \lambda_{e q}, h_{o}, h_{f}, h_{c v}$ 
are specified as boundary conditions. The steady-state and transient thermal characterization was then implemented.

\subsubsection{The Effective Thermal Conductivity of Air Gap}

Rotor rotation induces outside air into the air-gap between the rotor and the stator from the end side of the motor, performing in convection between the rotor and the stator. The thermal field is connected to the fluid field by the heat transfer of the rotor and the stator through the air-gap. This heat transfer is further influenced by the slotting and the surface roughness of the rotor and the stator. All these make calculating the temperature field even more difficult. Recognizing that, the effective thermal conductivity $\lambda_{e f}$ has been investigated [34-36]. The Reynolds number $R e_{g}$ in the air gap and critical Reynolds number $\operatorname{Re}_{c}$ are:

$$
\begin{gathered}
\operatorname{Re}_{g}=\frac{\omega_{r} \delta}{v}=\frac{2 \pi \delta n\left(R_{s i}-\delta\right)}{60 v}, \\
\operatorname{Re}_{c}=41.2 \sqrt{\frac{R_{s} i}{\delta}}
\end{gathered}
$$

where $\omega_{r}$ is the peripheral speed of the rotor, $4.387 \mathrm{~m} / \mathrm{s} ; n$ is the motor speed, $105 \mathrm{rpm} ; \delta$ is the air-gap length, $0.001 \mathrm{~m} ; v$ is the kinematic viscosity of air, $1.5 E^{-5} \mathrm{~m}^{2} / \mathrm{s}$, and $R_{s i}$ is the inner radius of the stator $0.4 \mathrm{~m}$. Then, we calculated $R e_{g}$ and $R e_{c}$ as 292.4 and 824 respectively, for our model. The air flow is laminar then the heat transfer mode is mainly that of conduction where $\lambda_{e f}$ can be treated as being equal to that of air $\lambda_{\text {air }}$. This leads to heat transfer of the stator to the rotor as conduction. However, we propose using the structure of the shaft with a spoke (duct) to cool the rotor.

\subsubsection{Equivalent Model of Stator Windings}

The complex geometry of stator winding and insulation material in the stator slot makes it practically difficult to model the actual physical geometry. This difficulty was explained by recognising all insulating materials in the slots as a single insulating layer attached to the slot wall [5]. Thus, an equivalent model of the stator slot can be shown in Figure 4. The equivalent thermal conductivity $\lambda_{e q}$ of the slot insulation can be represented as:

$$
\lambda_{e q}=\frac{\sum_{i=1}^{n} \delta_{i}}{\sum_{i=1}^{n} \frac{\delta_{i}}{\lambda_{i}}},
$$

where $\lambda_{i}(i=1,2,3, \ldots)$ is the average thermal conductivity of each insulated layer, and $\delta_{i}(i=1,2,3, \ldots)$ is the equivalent thickness of each insulated layer.

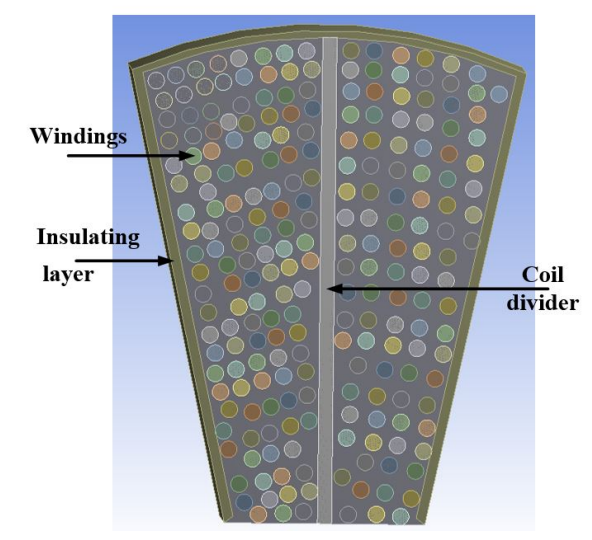

Figure 4. Equivalent model for stator slot. 


\subsubsection{Heat Transfer Coefficient between External Frame and Ambient}

The thermal resistance between the housing and ambient of the totally enclosed WJ with no fan is often the largest single resistance between winding and ambient. It hence represents a vital role in the precision of the thermal performance of the motor. It can be described as [32]:

$$
R_{o}=\frac{1}{A_{s} h_{o}},
$$

where $A_{s}$ is the surface area, and $h_{0}$ is the effective heat transfer coefficient due to natural convection and radiation.

\subsubsection{Forced Convection Heat Transfer Coefficient between End Winding and End-Caps}

In Reference [32], the heat transfer coefficient $\left(h_{f}\right)$ was obtained between end winding and end-caps as a performance of the inside air speed, as:

$$
h_{f}=6.22 \omega_{r} .
$$

\subsubsection{The Heat Transfer Coefficient of Water Jacket}

Considering the larger of the motor losses produced in the stator portion, the cooling type of totally-enclosed water-cooled is used in the SRM for better cooling. The stator core of the SRM is enfolded by the WJ with a spiral type water channel, as shown in Figure 5. A partial sectional view of the $3 \mathrm{D}$ thermal model is shown as Figure 5 including stator and rotor core, shaft spoke, stator windings and housing with water channels.

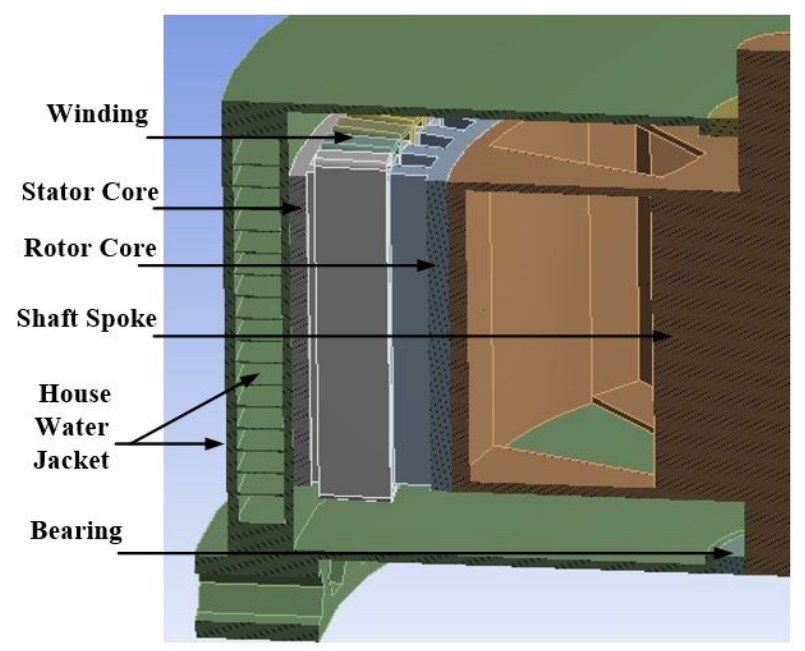

Figure 5. The sections of water jacket (WJ) with a spiral type water channel with the SRM.

The cooling system removes heat in order to maintain SRM operation within the desired temperature range. The cooling system has a direct influence on the process and service life of the SRM. Presume all the losses produced in the SRM can be dissipated by the cooling water according to Newton's law of cooling [2]. Hence, the maximum wall temperature of the WJ can be given as:

$$
P_{\text {loss }}=h_{c v} A_{s}\left(T_{\max }-T_{f}\right) .
$$

Moreover, the expression of the total quantity of heat generated in the SRM, that is lost due to the cooling water as given as:

$$
P_{\text {loss }}=\dot{m} C_{p}\left(T_{\text {outlet }}-T_{\text {inlet }}\right) \text {, }
$$


where $P_{\text {loss }}$ is total loss, [W], $C_{p}$ is specific heat at constant pressure of coolant, $\left[\mathrm{J} / \mathrm{kg}^{\circ} \mathrm{C}\right], \dot{m}$ is the mass flow rate of coolant, $[\mathrm{kg} / \mathrm{s}], T_{\max }$ is the maximum wall temperature of the $\mathrm{WJ},\left[{ }^{\circ} \mathrm{C}\right]$, and $T_{f}$ is the mean fluid temperature between the coolant inlet and outlet temperature, $\left[{ }^{\circ} \mathrm{C}\right] . T_{\text {outlet }}$ and $T_{\text {inlet }}$ are the inlet and an outlet temperature of the fluid $\mathrm{WJ},\left[{ }^{\circ} \mathrm{C}\right]$. Then, the value of the maximum temperature in the wall at operating point conditions is obtained as:

$$
T_{\max }=T_{f}+\frac{P_{\text {loss }}}{A_{s} h_{c v}}
$$

The product of $h_{c v}$ and $A_{s}$ surface heat transfer area can be determined as $h_{c v} A_{s}$ convection heat transfer factor for estimating the cooling capability. It is obvious that the bigger $h_{c v} A_{s}$, the smaller the temperature-rise occuring in the SRM under the condition that the total losses of the SRM are constant. The relation between $\dot{m}$, mass flow rate $[\mathrm{kg} / \mathrm{s}], Q$, volumetric flow rate $\left[\mathrm{m}^{3} / \mathrm{s}\right], V$ velocity of the fluid $\left[\mathrm{m}^{2} / \mathrm{s}\right], D_{h}$, hydraulic diameter $\left[\mathrm{m}^{2}\right]$, and Re, Reynolds number are given as follows:

$$
\begin{gathered}
Q=\frac{\dot{m}}{\rho}=V D_{h}, \\
D_{h}=\frac{2 H W}{(H+W)}, \\
\operatorname{Re}=\frac{\rho V D_{h}}{\mu}=\frac{2 V H W}{v(H+W)},
\end{gathered}
$$

where $H, W$ are the height and width of the water channel. The $h_{c v}$ strongly depends on Re. Thus, the $h_{c v} A_{s}$ value of WJ can be estimated based on empirical formulations for laminar $\operatorname{Re}<2300$, for transition $2300<\operatorname{Re}<4000$ and for turbulent $\operatorname{Re}>4000$ flow respectively as [32,36,37]:

$$
h_{c v} A_{s}= \begin{cases}\frac{3.66 k_{f} L N(H+W)^{2}}{H W} & R e \leq 2300, \\ \frac{0.012 k_{f} L N(H+W)^{2}}{H W}\left(R e^{0.87}-280\right)\left(P_{r_{f}}\right)^{0.4}\left(\frac{P_{r_{f}}}{P_{r_{w}}}\right)^{0.11}\left[1+\left(\frac{(2 H W)}{(H+W) L}\right)^{2 / 3}\right] & 2300<R e<10^{4}, \\ \frac{0.023 k_{f} L N(H+W)^{2}}{H W} \operatorname{Re}^{0.8} P_{r_{f}}^{0.4} & R e \geq 10^{4} .\end{cases}
$$

The surface heat transfer area for rectangular channels is defined as:

$$
A_{s}=2 N L(H+W),
$$

where $N$ is series number of the water channel in the WJ. The thermal entrance length can be estimated from [38]:

$$
\frac{L}{D_{h}}= \begin{cases}0.05 R e & R e \leq 2300, \\ 0.033 R e P_{r_{f}} & 2300<R e<10^{4} \\ 60 & R e \geq 10^{4} .\end{cases}
$$

When fluid flows inside a pipeline, the friction occurs between the moving fluid and the stationary pipe wall. Fluid head losses are commonly the outcome of two mechanisms: friction along the pipe walls, head losses alongside the channel wall are called friction losses due to friction, and losses due to turbulence within the bulk fluid are called minor losses, which can be calculated by the Darcy-Weisbach equation respectively. 


$$
\begin{gathered}
H_{f}=\xi \frac{L V^{2}}{2 g D_{h}}, \\
H_{J}=\zeta \frac{V^{2}}{2 g},
\end{gathered}
$$

where $\xi$ and $\zeta$ are the frictional and local head loss coefficient, which depend on Re and relative roughness. They are very important since the $V$ velocity and $h_{c v}$ of the WJ is influenced by these design parameters. Figure 6 shows the investigation into the influence of the series number of the water channel on the hydraulic diameter of the WJ, for $N$ in the range (1 to 21), at a constant height of the water channel. It is evident that the hydraulic diameter of the WJ decreases, when the $N$ of the water channel increases. Moreover, the width of the water channel is defined as:

$$
W_{N}=\frac{W_{t}-(N-1) S}{N}
$$

where $S$ is space between channels, $W_{t}$ is the total width of WJ.

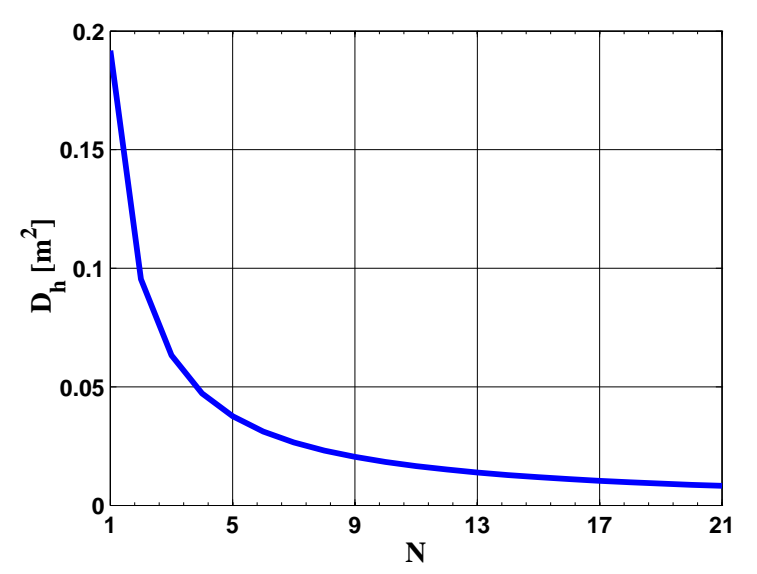

Figure 6. The hydraulic diameter of WJ with the series number of the water channel.

The dimensions of the water channel ( $H$ and $W$ ) can be calculated through Equations (13) to (21), hence, the results are shown in Figures 7 and 8 . The fluid velocity of WJ increases as the hydraulic diameter of the WJ decreases, as shown in Figure $7 \mathrm{a}$. Figure $7 \mathrm{~b}-\mathrm{d}$ show that the increase in velocity leads to the Reynolds number, the convection heat transfer coefficient, and fluid head losses increasing remarkably. It is evident with volumetric flow increase in the range $0.006 \mathrm{~L} / \mathrm{s}$ to $0.6 \mathrm{~L} / \mathrm{s}$; all values are increased, such as the fluid velocity and the head losses. Moreover, the total head loss of the fluid can exceed the constraint $(10 \mathrm{kPa})$ for the $N$ greater than 17 at the volumetric flow rate is $0.6 \mathrm{~L} / \mathrm{s}$.

Figure 8 illustrates the investigation into the influence of the WJ height ( $40 \mathrm{~mm}$ to $49 \mathrm{~mm}$ ), and a number of water channels (1 to 21), on convection heat transfer analysis of $\mathrm{WJ}$ at constant flow rate $0.6 \mathrm{~L} / \mathrm{s}$. Considering the maximum convection heat transfer and design constraint on fluid losses with restriction limited to $(10 \mathrm{kPa})$, the dimensions of the water channel $(H$ and $W)$ can be obtained, and the result is shown in Figure 8a-d.

As can be seen in Figure $8 \mathrm{~d}$, the WJ has a height of more than $40 \mathrm{~mm}$ and $(N)$ may be less than 21 channels. The total water head loss can exceed the constraint $(10 \mathrm{kPa})$ at the volumetric flow rate of $0.6 \mathrm{~L} / \mathrm{s}$, when $(N)$ is greater than 17. Furthermore, as shown in Figure $8 \mathrm{c}$, the range of $h_{c v}$ for a number of water channels ( 1 to 21 ) can be identified. The proposed structure of the $72 / 48$ SRM in Figure 1 shows the $\mathrm{WJ}$ has one inlet and one outlet configuration, on two different sides. This means that the WJ must have a configuration with odd channels. Thus, the approximate range of $h_{c v}$ for odd 
channel $(N)$ is presented in Table 5 . From Table 5, the convection heat transfer coefficient $\left(h_{c v}\right)$ value for 17 channels is the highest realistic value, whilst in 19 channels the fluid loss would be significantly higher. For comparison, it can be seen that the minimum of $h_{c v}$ for 17 channels is approximately twice and quarter of the value of 9 and 5 channels, respectively. For this reason, 5, 9 and 17 channels are chosen, also 1 channel is also chosen as a benchmark. Based on previous descriptions and calculations, the limitations of configuration dimensions of WJ are proposed and presented in Table 6 . The four proposal structures are simulated using ANSYS-CFD. The $\left(h_{c v}\right)$ at various convective surfaces inside the motor for the four proposed structures of WJ were obtained using the CFD method.

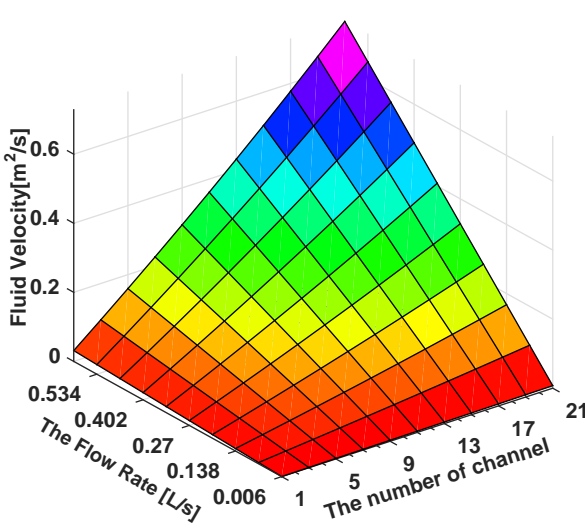

(a)

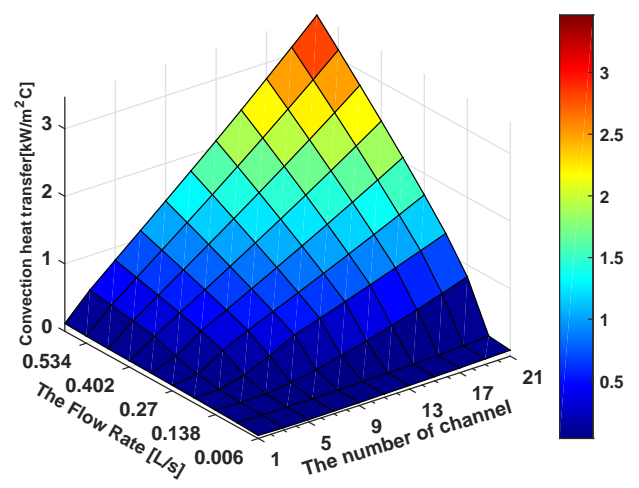

(c)
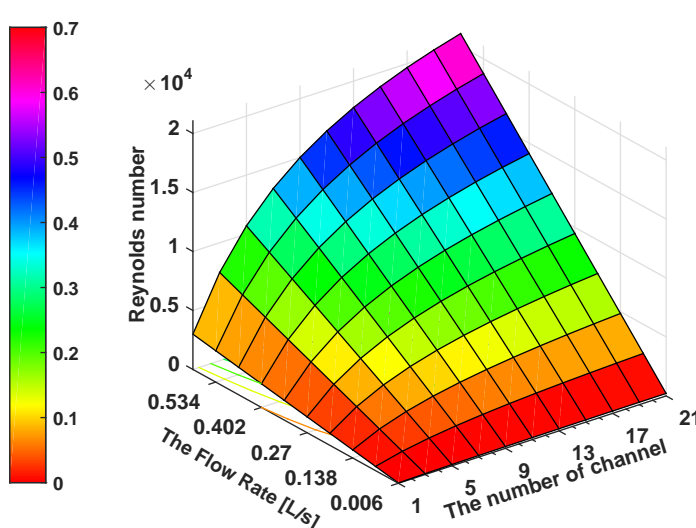

(b)

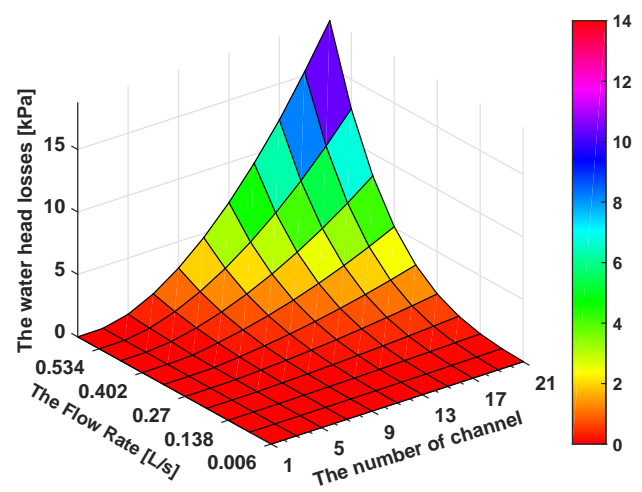

(d)

Figure 7. Variations of the convection heat transfer analysis of WJ when changing the number of channel and flow rate simultaneously. (a) Fluid velocity; (b) Reynolds number; (c) convection heat transfer; (d) the water head losses.

Table 5. The approximate range of $h_{c v}$ for odd number of water channels for the SRM.

\begin{tabular}{llll}
\hline WJ Channel & $\begin{array}{l}\text { The Range of } h_{c v} \\
\mathbf{k W} / \mathbf{m}^{\mathbf{2}}{ }^{\circ} \mathbf{C}\end{array}$ & WJ Configurations & $\begin{array}{l}\text { The Range of } h_{c v} \\
\mathbf{k W} / \mathbf{m}^{2 \circ} \mathbf{C}\end{array}$ \\
\hline 1 channel & $0<h_{c v}<0.4$ & 3 channels & $0.4<h_{c v}<0.7$ \\
5 channels & $0.7<h_{c v}<1$ & 7 channels & $1<h_{c v}<1.3$ \\
9 channels & $1.3<h_{c v}<1.6$ & 11 channels & $1.6<h_{c v}<1.9$ \\
13 channels & $1.9<h_{c v}<2.2$ & 15 channels & $2.2<h_{c v}<2.5$ \\
17 channels & $2.5<h_{c v}<2.8$ & 19 channels & $2.8<h_{c v}<3.1$ \\
\hline
\end{tabular}




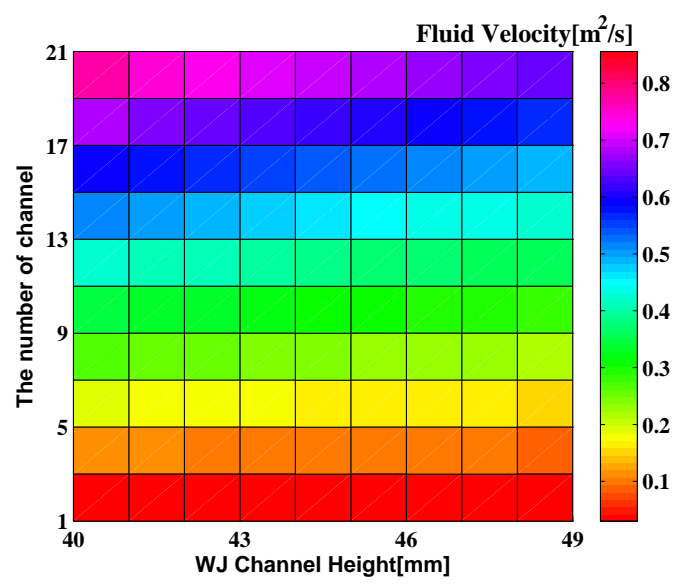

(a)

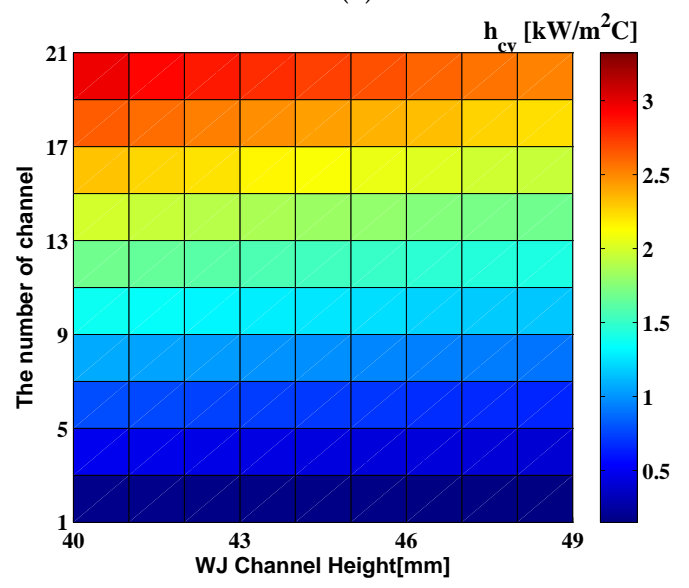

(c)

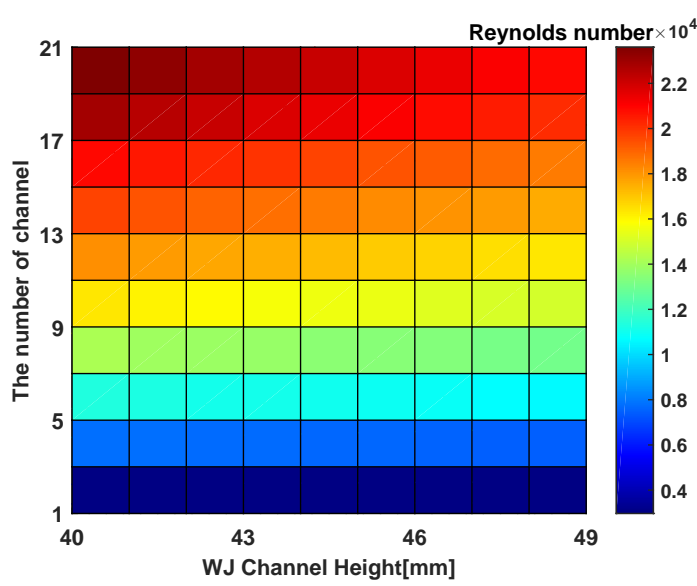

(b)

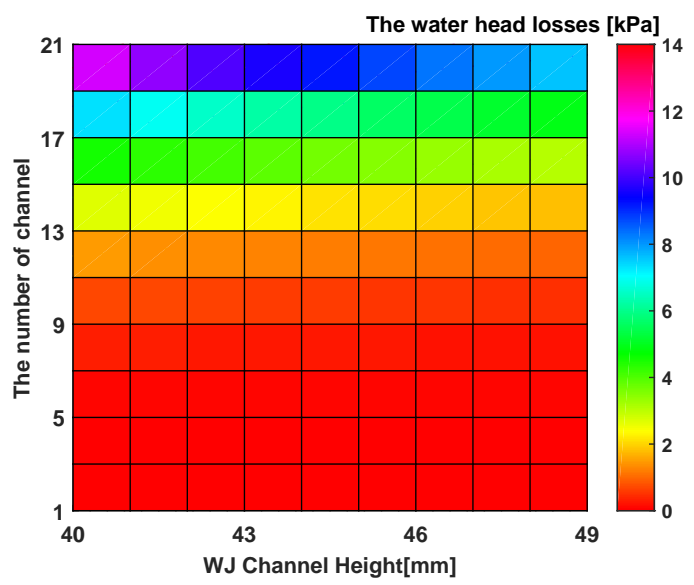

(d)

Figure 8. Variations of the convection heat transfer analysis of WJ when changing the channel height and number of a channel simultaneously. (a) Fluid velocity; (b) Reynolds number; (c) convection heat transfer; (d) the water head losses.

Table 6. The proposal dimensions of the water jacket configuration.

\begin{tabular}{lll}
\hline WJ Channel & $\mathbf{H}[\mathbf{m m}]$ & $\mathbf{W}[\mathbf{m m}]$ \\
\hline 1 channel & 47 & 380 \\
5 channels & 47 & 74.4 \\
9 channels & 47 & 40.44 \\
17 channels & 47 & 20.47 \\
\hline
\end{tabular}

\section{Thermal Analysis Methods}

Thermal analysis methods of electrical machines can be classified into two essential types: numerical and analytical lumped-circuit techniques. Numerical analysis is an attractive approach, as very complex geometries can be modelled, hence, the heat transfer can be accurately determined. There are two types of numerical analysis: the FEA and the CFD. The CFD has the benefit that it can be utilized to predict flow in multiple regions, as around the motor end windings.

\section{Numerical Analysis-CFD Analysis for Water Jacket}

The CFD model was applied to studying the convective cooling inside the 72/48 SRM due to the flowing water, therefore calculating $h_{c v}$ for the water jacket (WJ). The 3D CFD is the best alternative for the flow process in an electrical machine. The 3D numerical simulations of CFD mode for four WJ 
configurations with different numbers of channels were performed. The geometrical modelling was carried out on an ANSYS-Design-Modeler, the unstructured, and structured grids are used in the paper. The SRM was meshed by a structured grid due to complex structures. There were 27,265,153 mesh cells in the simulations. With the use of the spiral WJ type, the coolant flows along the cylinder vertically, the coolant enters the cylinder from the bottom side and flow out from the head of the opposite side. The coolant used in this calculation was water at a temperature of $26^{\circ} \mathrm{C}$ and the ambient temperature was $26^{\circ} \mathrm{C}$. The convection heat transfer coefficient between the motor's outside surface and the air is $5 \mathrm{~W} / \mathrm{m}^{2}{ }^{\circ} \mathrm{C}$. The inlet and outlet boundary conditions of the coolant are defined as a mass flow inlet $(0.6 \mathrm{~L} / \mathrm{s})$ at a temperature of $26^{\circ} \mathrm{C}$ and pressure outlet respectively. The wall boundary conditions as solid regions including stator, rotor and winding are set to heat flux boundary conditions. These wall boundary conditions were set to heat flux boundary conditions in our model. The winding's heating power was $6560 \mathrm{~W}$, stator and the rotor's core heating power were $1445 \mathrm{~W}$ and $650 \mathrm{~W}$, respectively. The losses of the stator, the rotor with winding copper loss were mapped directly to the model. For the application described in this research, the $k-\varepsilon$ model was used for its robustness and simplicity.

WJ is widely used for the high-power induction motor (IM) and interior permanent synchronous motor (IPMSM) [39,40]. Based on the same principle, an analytical method and numerical method were used in this work to obtain the machine's temperature rise. The temperature rise for the 72/48 SRM was achieved under the rated load and the rated speed. Figure 9 shows the 3D model structure of WJ configurations, with four different numbers of channels, such as 1, 5, 9 and 17 channels. Moreover, the direction of the arrow shows the direction of water flows.

Figures 10 and 11 show the 3D models' steady-state temperature profile of WJ configurations, with four different numbers of channels; $1,5,9$ and 17 for a water flow rate of $0.6 \mathrm{~L} / \mathrm{s}$. The most significant temperature zone inside the SRM was at the stator winding close to the outlet towards where the fluid exits the cooling jacket. The rate of heat transfer is specifically proportionate to the temperature difference, and as the water flows from the inlet towards the outlet, it absorbs heat, which increments its temperature. This leads to lesser temperature differences towards the end. Hence, it decreased the amount of heat transfer as water flows toward the outlet, resulting in the most significant temperature zone towards the end of the coolant flow loop. Figures 10a and 11a show the outer portion of the stator winding displays are asymmetric. The temperature of the side of end winding near the inlet and outlet is $\left(78^{\circ} \mathrm{C}\right)$ and $\left(94^{\circ} \mathrm{C}\right)$, respectively. This situation can be explained based on water flow behavior in the casing of the water jacket for 1 channel. However, the temperature field is still non-uniform and asymmetric in the rotor. There is little difference between 5 and 9 channels; the temperature field is still asymmetric in stator winding, shown in Figures $10 \mathrm{~b}, \mathrm{c}$ and $11 \mathrm{~b}, \mathrm{c}$.

The high temperatures in the stator winding decrease as the $N$ is increment, when $N$ becomes greater than 17 , the lowering of the temperature becomes less effective. When the number of channels is 17 , the temperature field is uniform and symmetric in the stator, rotor and winding at the same time, the heat dissipation of the cooling system is improved, and the result is shown in Figures 10d and 11d.

Table 7 includes a comparison between the heat transfer coefficients $h_{c v}$ obtained by the numerical and analytical solutions. In this case, the numerical coefficients are lower than the analytical results. Clearly, an agreement is found between the two sets of results, confirming the numerical models are effective. The former results are more accurate than the latter. The increment in the number of the channel at a fixed water flow rate increases the average velocity of the water over the SRM surface resulting in an increment of the $h_{c v}$, as shown in Figure 12. This results in the lowering of the overall temperature field and the maximum temperature inside the SRM. For a constant flow rate, the mean velocity of the coolant is directly proportional to the number of channels resulting in an increase in the jacket surface friction losses. The downside of increasing the number of channels is that it increases the SRM pumping power. The economic aspects of pump capacity required for coolant circulation should be considered as well [39]. Therefore, we recommend used the structure of WJ configurations, with 17 channels. 


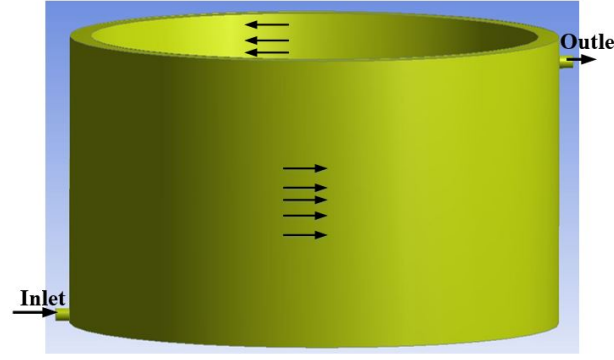

(a)

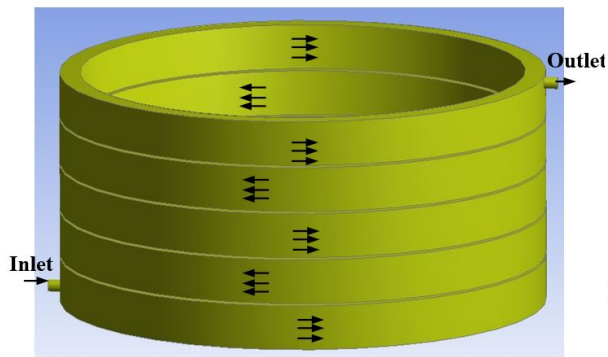

(c)

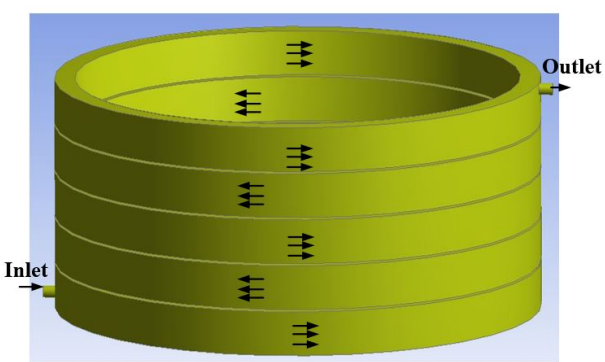

(b)

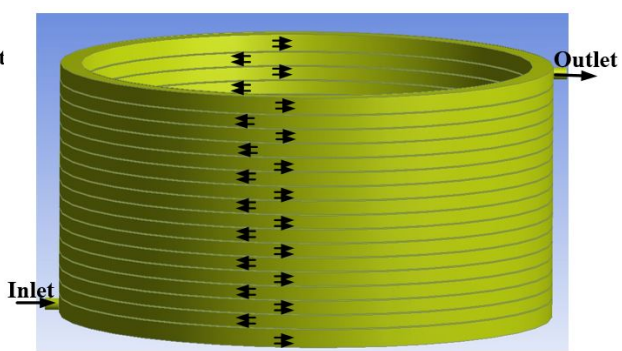

(d)

Figure 9. The 3D models structure of WJ configurations. (a) 1 channel; (b) 5 channels; (c) 9 channels; (d) 17 channels.

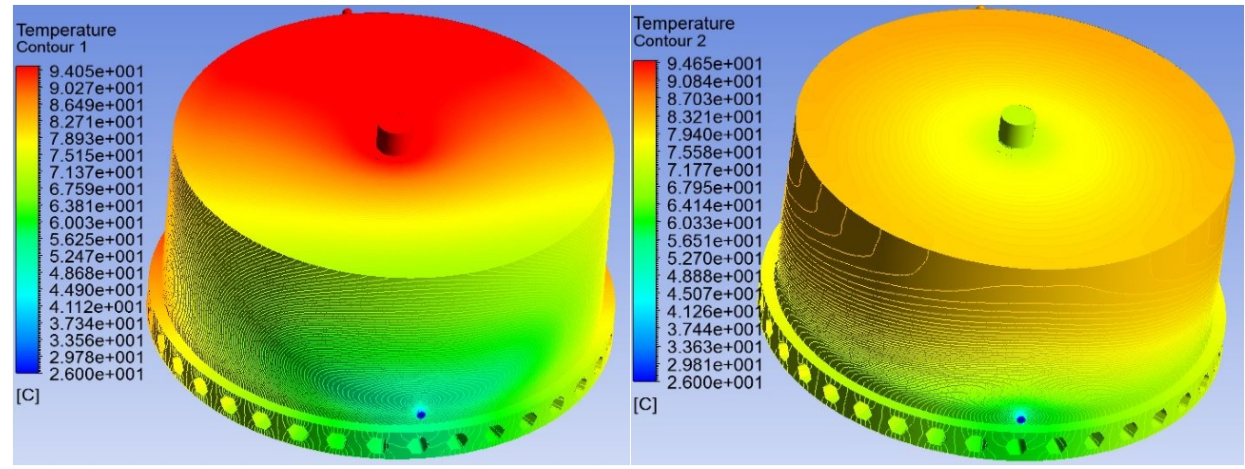

(a)

(b)

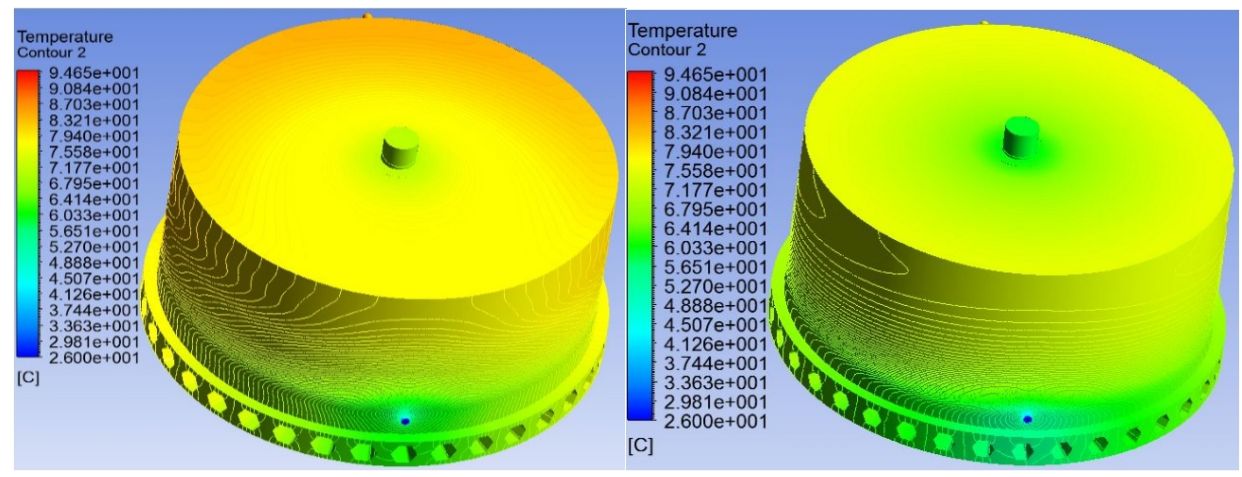

(c)

(d)

Figure 10. The 3D models temperature profile of WJ configurations. (a) 1 channel; (b) 5 channels; (c) 9 channels; (d) 17 channels. 


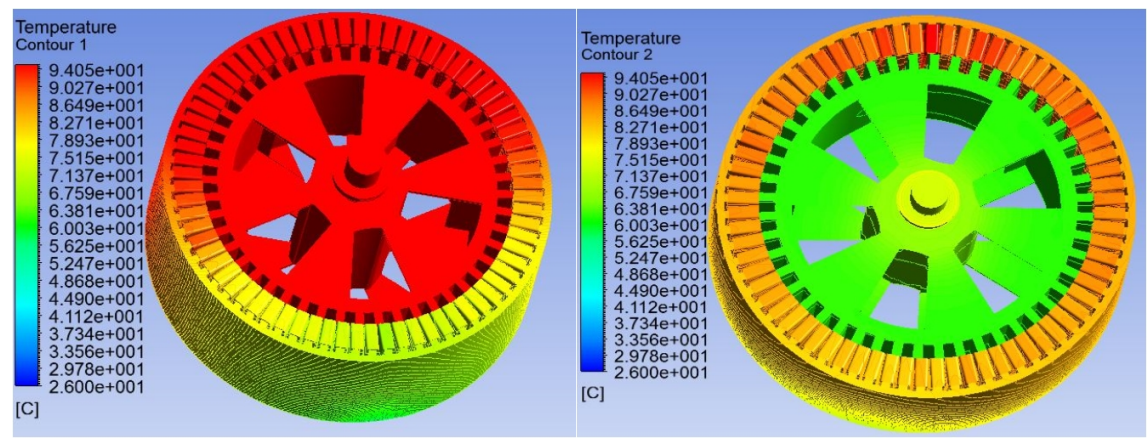

(a)

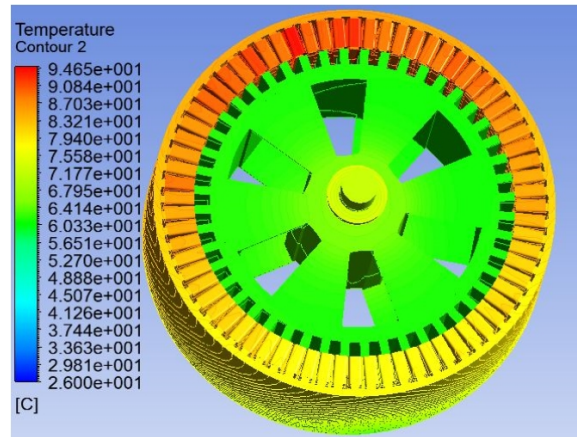

(c) (b)

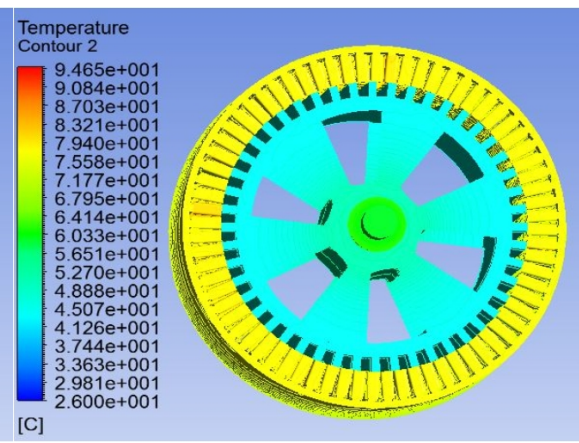

(d)

Figure 11. The 3D models temperature profile of the 72/48 SRM. (a) 1 channel; (b) 5 channels; (c) 9 channels; (d) 17 channels.

Table 7. A comparison of the heat transfer coefficients obtained by numerical and analytical solutions.

\begin{tabular}{lll}
\hline WJ Configurations & $\begin{array}{l}\text { Analytically } \\
\mathbf{W} / \mathbf{m}^{2 \circ} \mathbf{C}\end{array}$ & $\begin{array}{l}\text { Numerically } \\
\mathbf{W} / \mathbf{m}^{2 \circ} \mathbf{C}\end{array}$ \\
\hline 1 channel & 351 & 349 \\
5 channels & 722 & 718 \\
9 channels & 1630 & 1621 \\
17 channels & 2589 & 2578 \\
\hline
\end{tabular}

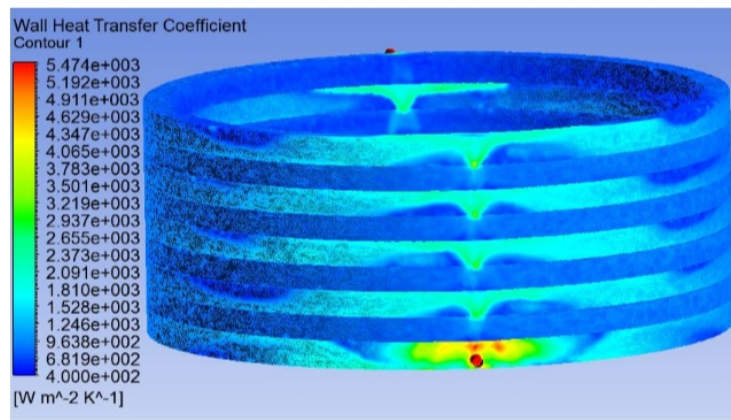

(a)

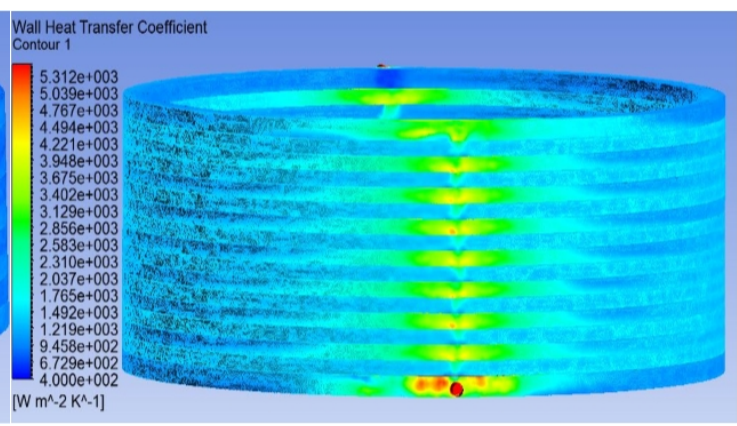

(b)

Figure 12. The heat transfer coefficient distribution of the two WJ configurations. (a) 9 channels; (b) 17 channels.

The structure of the shaft with spoke (duct) for cool the rotor is presented in Figures 10 and 11. The boundary condition of the part of the shaft, which is affected by the hole in the 3D model, is modeled, with the convection heat transfer coefficient $\left(5 \mathrm{~W} / \mathrm{m}^{2}{ }^{\circ} \mathrm{C}\right)$ on the surfaces of it. Figure 13 shows the 3D temperature profile of WJ configurations, with a different structure of shaft, spoke, and a solid shaft. The benefit of the used spoke shaft is that its causes the rising temperature of shaft 
and rotor to decrease. Moreover, it lowers the overall temperature field inside the SRM, as shown in Figure 13.

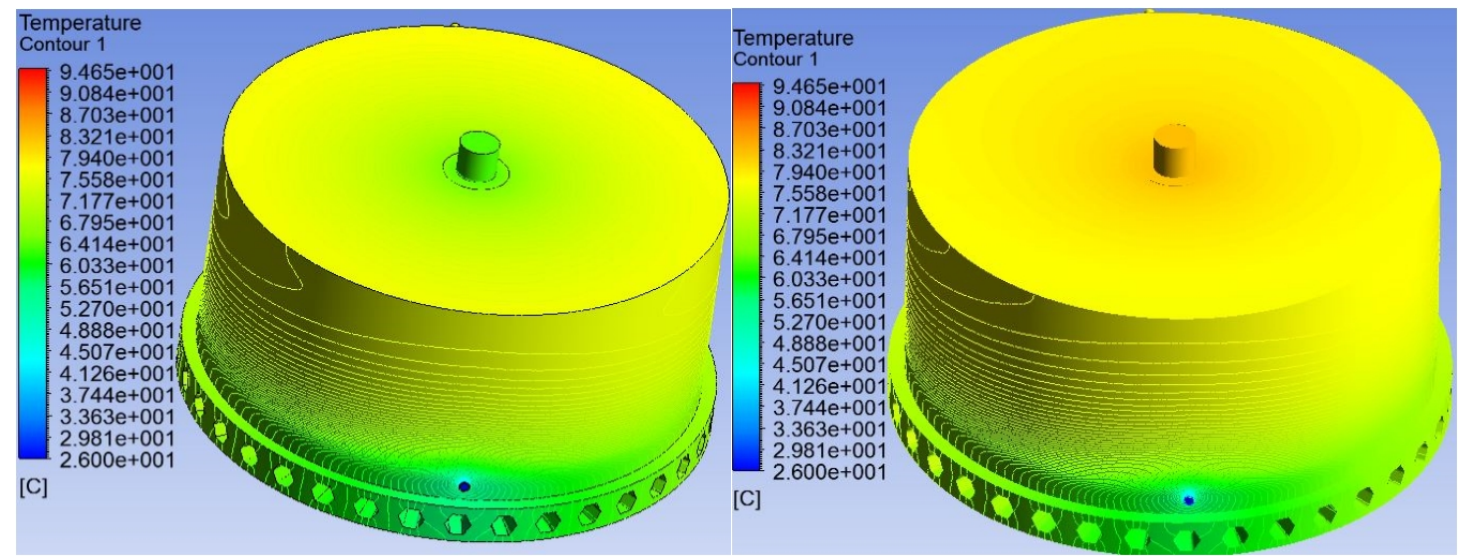

(a)

(b)

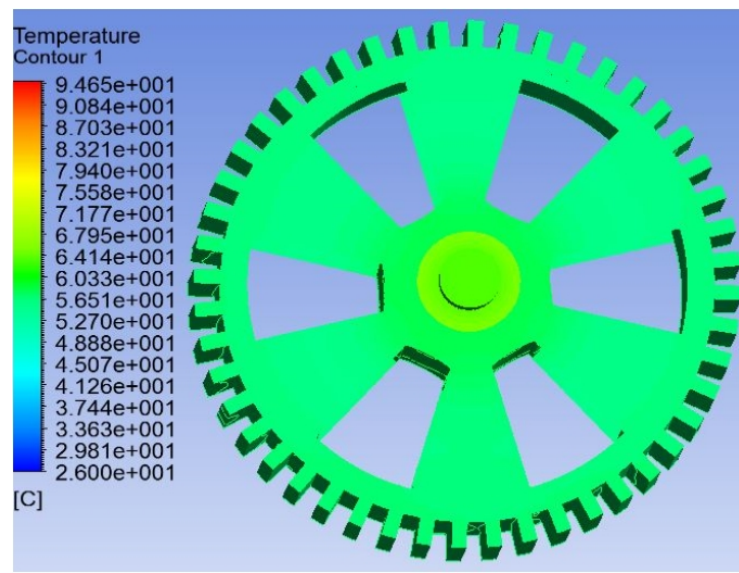

(c)

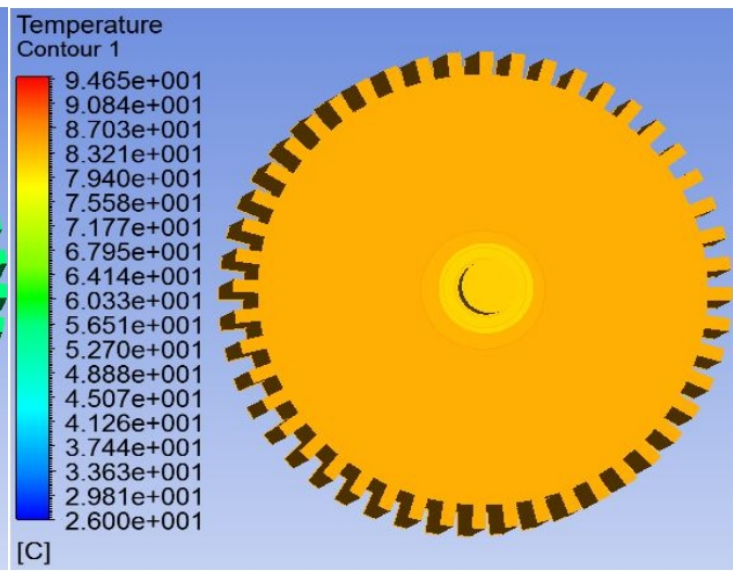

(d)

Figure 13. The 3D models temperature profile of WJ configurations. (a) 17 channels with spoke shaft; (b) 17 channels with solid shaft; (c) rotor with spoke shaft; (d) rotor with a solid shaft.

\section{Mechanical Analysis}

The vibration performances of SRM depend on two features-the radial force and the SRM structural characteristics. The frequency of a natural vibration in an elastic body is called the natural frequency. There are many reasons to calculate the natural frequencies and mode shapes of a structure prototype SRM. One reason is to avoid the resonance problem. In the SRM, it is found that resonance occurs if the phase frequency or the harmonics coincide with the SRM natural frequency. The phase frequency is given as:

$$
F_{p}=\frac{\omega_{m} P_{r}}{2 \pi}
$$

where $\omega_{m}$ is the speed $[\mathrm{rad} / \mathrm{s}]$ and $P_{r}$ is the number of rotor poles. Vibration is the maximum when any frequency of the harmonics $F_{n}=n F_{p}$ is coincident with the SRM natural frequency. In References [1,15], the first mode frequency $\omega_{f m}^{2}$ of the SRM is given by:

$$
\omega_{f m}^{2}=\frac{E b_{s y}^{2}}{6 \rho\left(1-\gamma^{2}\right)\left(\frac{\pi^{2}}{4}-2\right)\left(\frac{D_{o}-b_{s y}}{2}\right)^{4}},
$$


where $D_{o}$ and $b_{s y}$ are the outer diameter of the stator lamination stack and the stator yoke thickness, $\gamma$ is the Poisson ratio, $E$ is the modulus of elasticity and $\rho$ is the mass density of the lamination material.

The radial and tangential forces are the components of the air-gap electromagnetic force. The useful forces are the tangential ones; they are producing the torque. The radial force caused by the interaction of doubly salient teeth, during phase winding is excited, will lead to vibration of the motor $[17,18,41]$. The tangential force $F_{t}$ and the major force of mechanical deformation in the motor which is called the radial force $F_{r}$, they are given as:

$$
\begin{gathered}
F_{t}=\iint \frac{1}{\mu_{o}}(\vec{B} \cdot \hat{n}) \vec{B} d S=\frac{1}{\mu_{o}} \iint\left(\vec{B}_{r} \vec{B}_{t}\right) d S, \\
F_{r}=\iint \frac{1}{2 \mu_{o}} \nabla B^{2} \hat{n} d S=\frac{1}{2 \mu_{o}} \iint\left(B_{r}^{2}-B_{t}^{2}\right) d S,
\end{gathered}
$$

where $B$ is flux density, $\hat{n}$ is the unit normal vector, $B_{r}$ and $B_{t}$ are the radials and tangential component of the flux density in the air gap respectively. A 2D finite element models for the SRM has been developed, to obtain the waveforms and the Fast Fourier Transform (FFT) of the radial force, as shown in Figure 14. The developed SRM is in 72/48 combination. Thus, the fundamental component of the phase current is $84 \mathrm{~Hz}$ at $105 \mathrm{rpm}$. The SRM was simulated for a $174 \mathrm{~A}$ DC current at $105 \mathrm{rpm}$, producing torque of $7.28 \mathrm{kNm}$, such that the high magnitude of the radial force was $1.46 \mathrm{kN}$, around the fundamental operating frequencies.

The numerical model of 3-phase 72/48 SRM was analyzed using the 3D FEA model to obtain the natural frequencies of the motor with two different structures of the shaft. The comparison between the results of these two different structures is presented in Table 8. It must be mentioned here that these natural frequencies vary depending on the boundary condition and the structure of the housing. Besides, the spoke shaft is much more weight-efficient than a solid shaft. This explains why the natural frequencies of a spoke shaft are greater than that of a solid shaft, as can be seen in Table 8. Figure 15 shows the total deformation of the 72/48 SRM with two different structures of the shaft at different frequencies. It can be observed that the minimum deformation is at the support points of the housing, and it increases gradually to reach a maximum at the top side of the housing. Figure 15 also shows that the total deformation of the SRM with a spoke shaft is larger than the deformation of SRM with a solid shaft. The minimum $\backslash$ maximum total deformations for the two shaft structures at various natural frequencies are clearly given in Table 9.

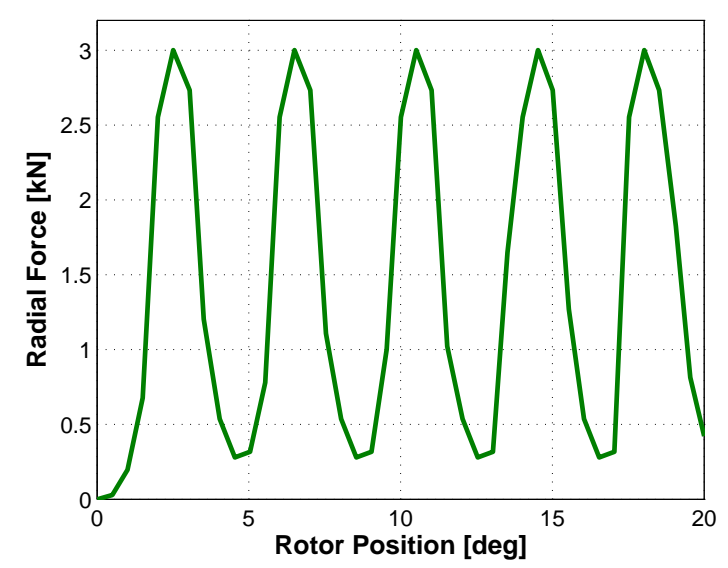

(a)

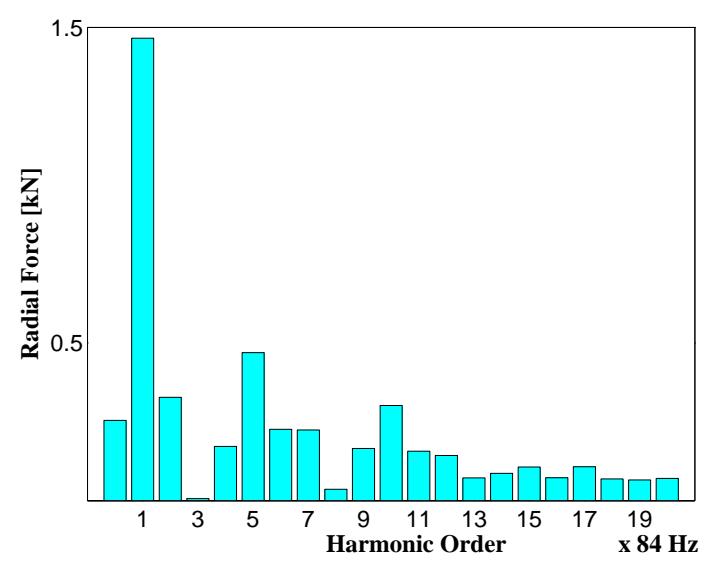

(b)

Figure 14. The radial force of the 72/48 SRM. (a) FEM of radial force versus Electric rotor potion; (b) Radial force fast Fourier transform. 
Table 8. The first six natural frequencies for the SRM with spoke and solid shaft.

\begin{tabular}{lllllll}
\hline Mode Shape & M-1 & M-2 & M-3 & M-4 & M-5 & M-6 \\
\hline Natural frequency of SRM with spoke shaft (Hz) & 508.64 & 516.56 & 748.64 & 800.23 & 859.18 & 872.78 \\
Natural frequency of SRM with solid shaft (Hz) & 407.72 & 412.14 & 423.85 & 440.82 & 463.01 & 549.34 \\
\hline
\end{tabular}

Table 9. A comparison of the total deformation for the SRM with spoke and solid shaft at various natural frequencies.

\begin{tabular}{lllll}
\hline \multirow{2}{*}{ Mode Shape } & M-1 & & M-2 & \\
& Min & Max & Min & Max \\
\hline Deformation of the SRM with spoke shaft $(\mathrm{mm})$ & 0 & 1.59 & 0 & 1.62 \\
Deformation of the SRM with solid shaft $(\mathrm{mm})$ & 0 & 1.09 & 0 & 1.54 \\
\hline
\end{tabular}

The radial forces determined from the electromagnetic FEA were entered into the mechanical FEA. Full mode harmonic analysis methods were applied to perform the analysis. The frequency range was specified as 0 to $1 \mathrm{kHz}$ with 25 solution intervals for the frequency resolution of $41.7 \mathrm{~Hz}$. The directional profile of deformation and acceleration were carried out with two different structures of the shaft and the results were shown in Figures 16-19, respectively. It is worth mentioning that the peaks directional deformation and acceleration emerged as natural frequencies mode- $2(516 \mathrm{~Hz})$ and mode- $5(859 \mathrm{~Hz})$ for the SRM with spoke shaft as shown in Figures 16 and 17. However, mode-3, which is 748.64 Hz, given in Table 8, is damped by the stator structure. Similarly, Figures 18 and 19 show the prototype of the SRM with the solid shaft; it had peak directional deformation and acceleration emerges from natural frequencies mode- $2(412 \mathrm{~Hz})$ and mode- $5(463 \mathrm{~Hz})$. The peak values of directional deformation and acceleration for a spoke shaft were greater than that of a solid shaft. However, those values occurred to a higher frequency, about six times that of the phase frequency $(84 \mathrm{~Hz})$.

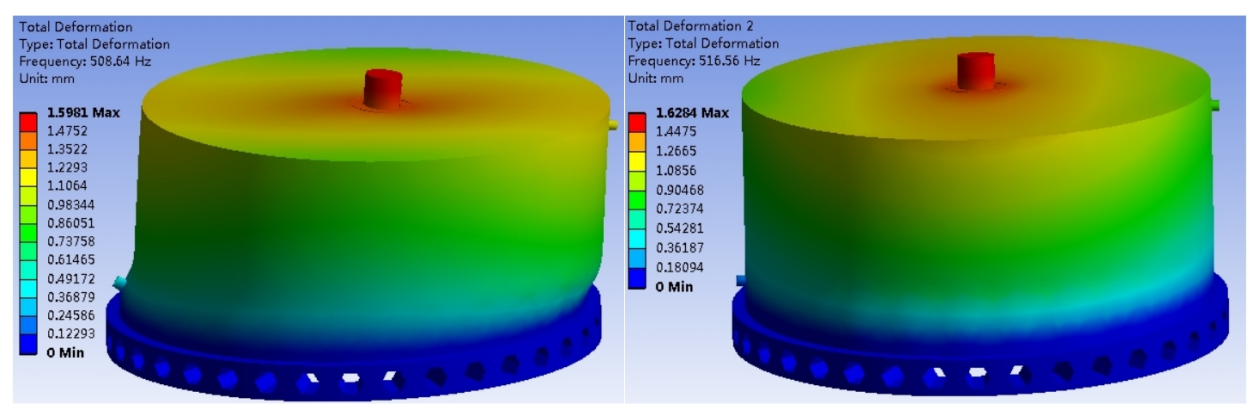

(a)

(b)

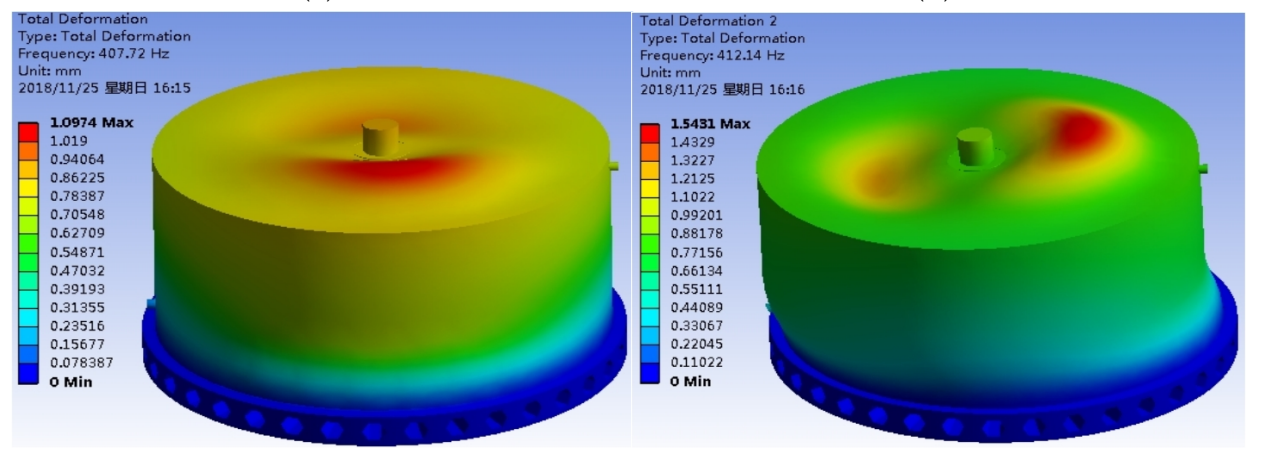

(c)

(d)

Figure 15. The total deformation of the $72 / 48$ SRM at various frequencies. (a) first mode shape $(508.64 \mathrm{~Hz})$ of SRM with spoke shaft; (b) second mode shape $(516.56 \mathrm{~Hz})$ of SRM with solid shaft; (c) first mode shape $(407.72 \mathrm{~Hz})$ of SRM with solid shaft; (d) second mode shape $(412.14 \mathrm{~Hz})$ of SRM with solid shaft. 


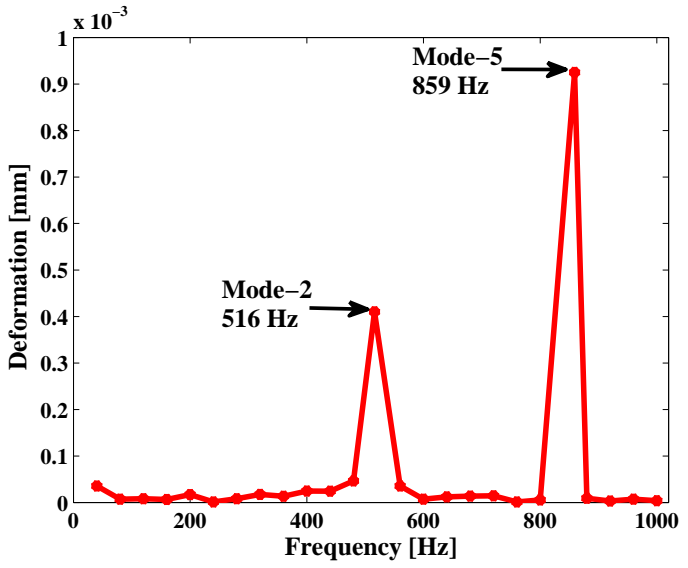

(a)

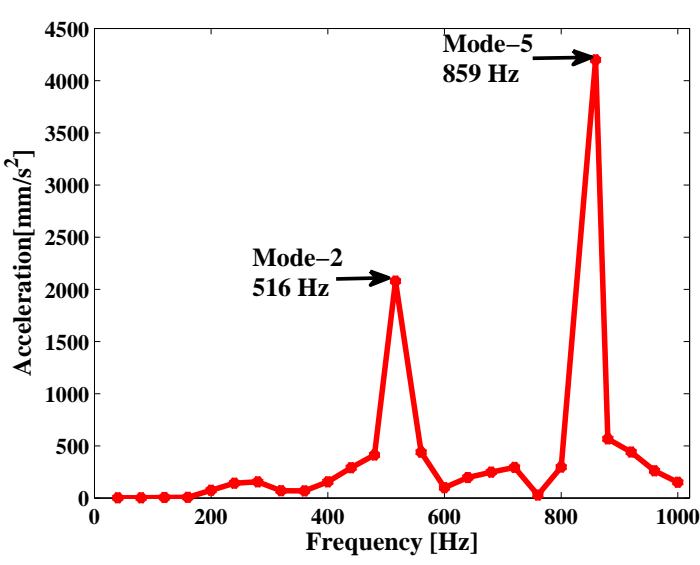

(b)

Figure 16. The directional deformation and acceleration for the SRM with spoke shaft. (a) Frequency response of the directional deformation; (b) frequency response of the directional acceleration.

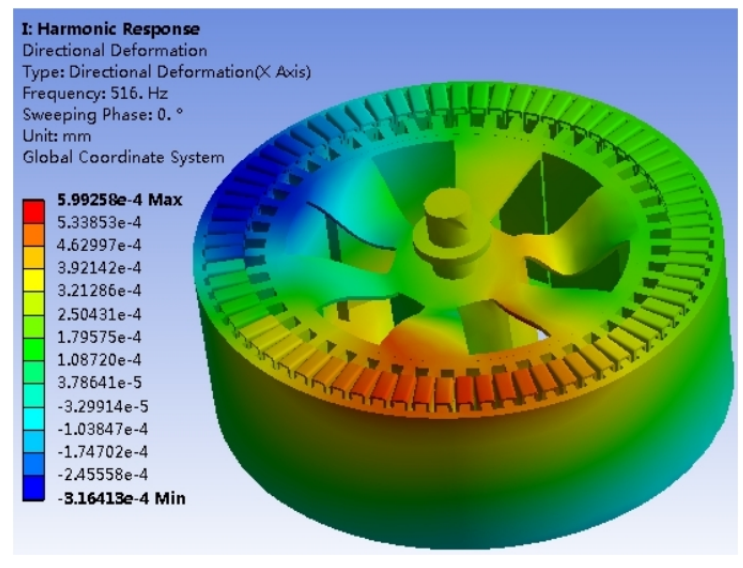

(a)

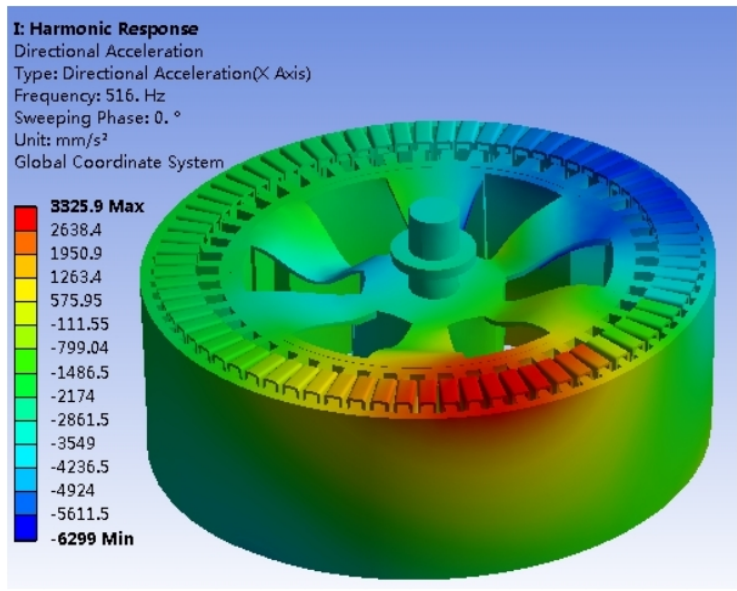

(c)

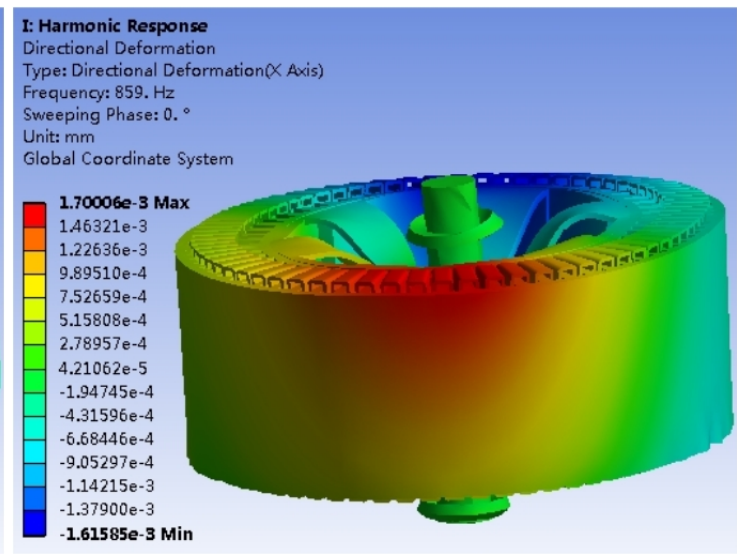

(b)

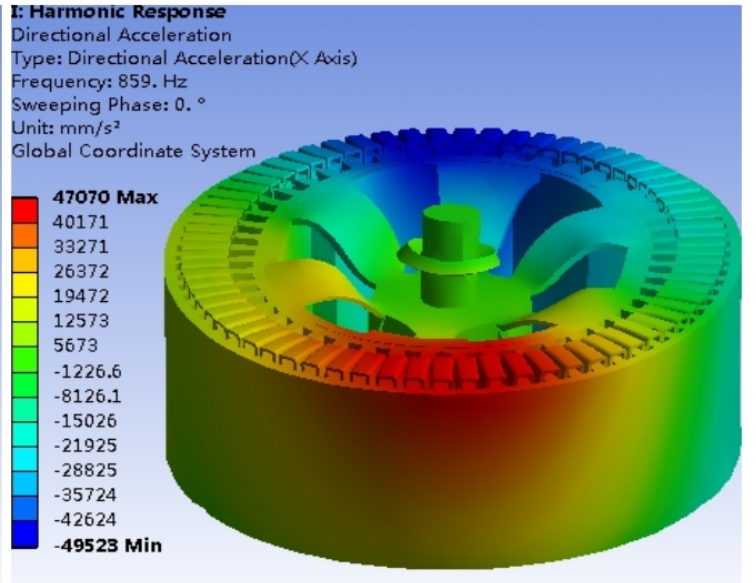

(d)

Figure 17. The directional deformation and acceleration for the SRM with spoke shaft. (a) The directional deformation of mode-2; (b) the directional deformation of mode-5; (c) the directional acceleration of mode-2; (d) The directional acceleration of mode-5. 


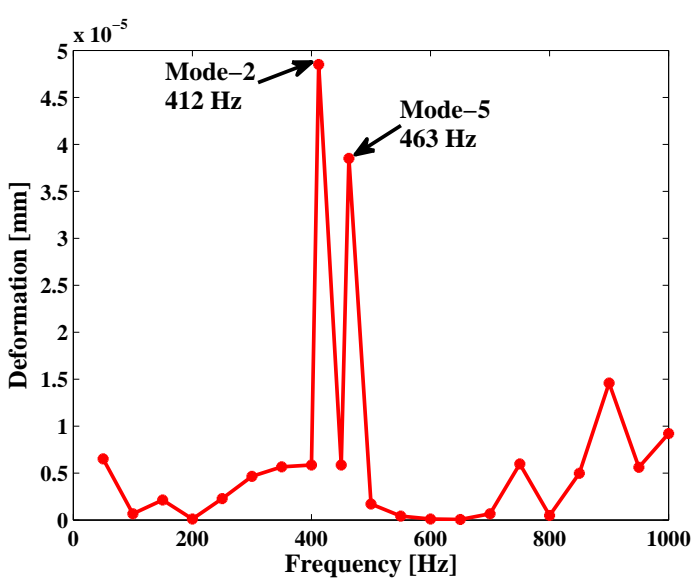

(a)

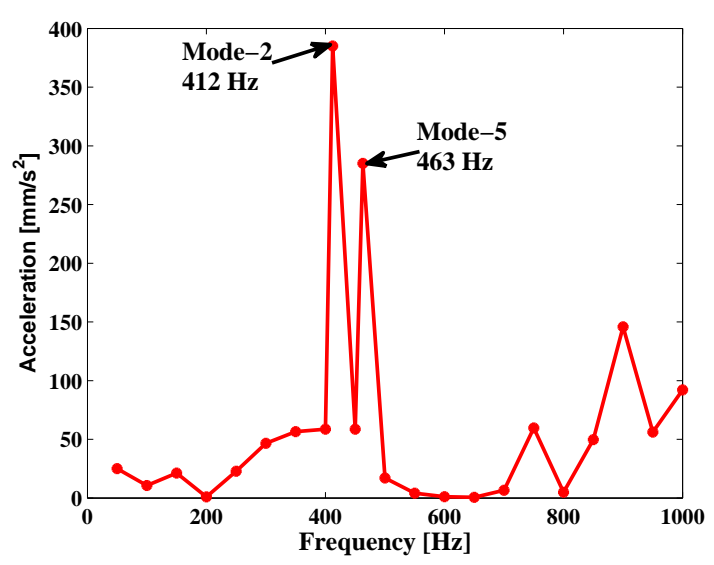

(b)

Figure 18. The directional deformation and acceleration for the SRM with solid shaft. (a) Frequency response of the directional deformation; (b) frequency response of the directional acceleration.

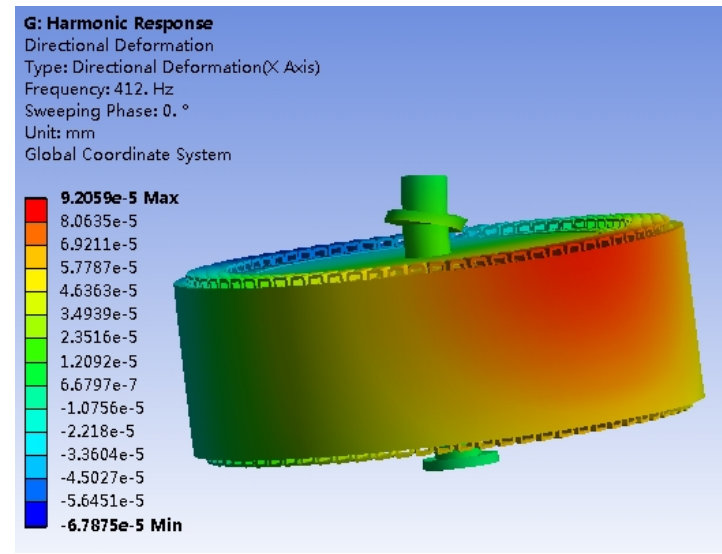

(a)

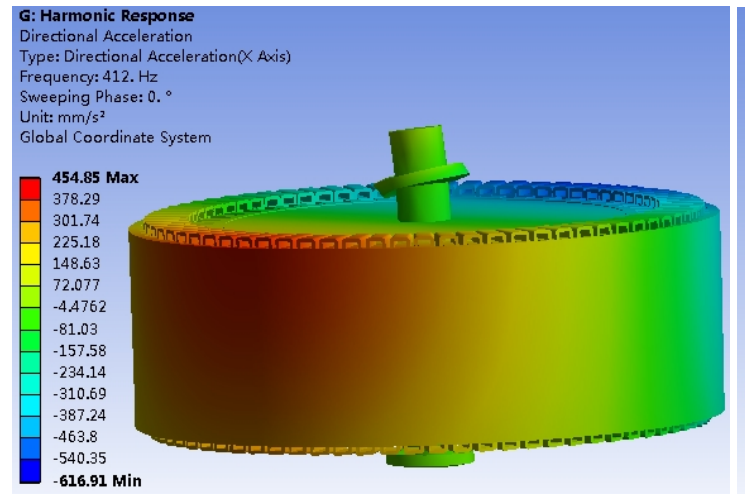

(c)

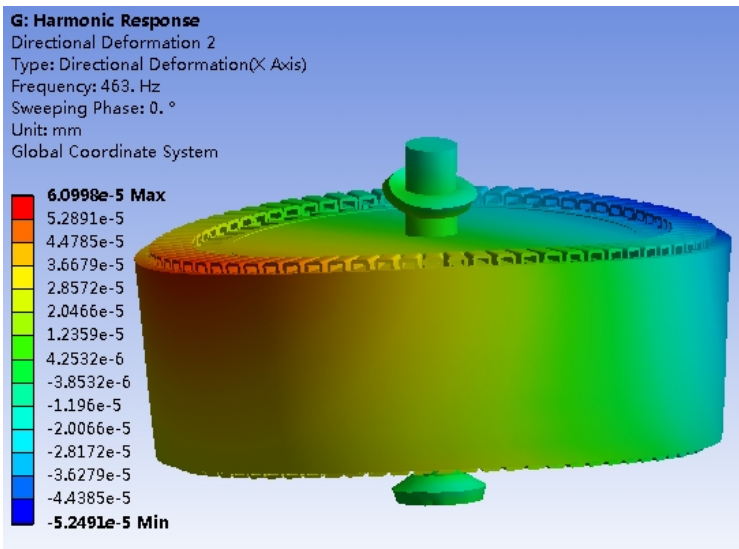

(b)

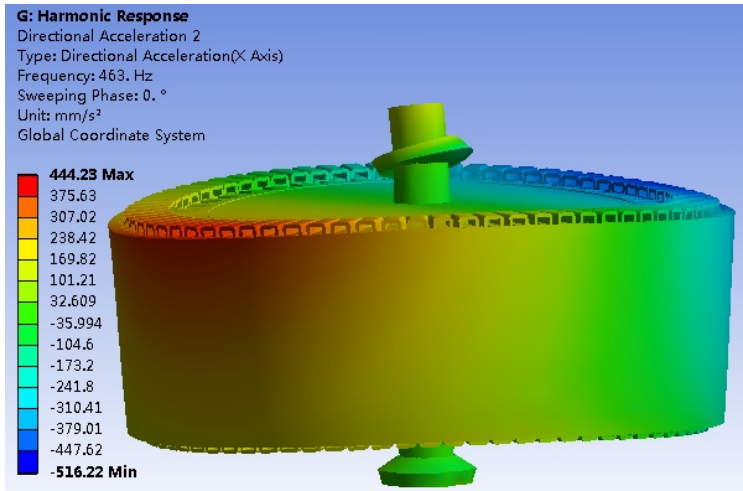

(d)

Figure 19. The directional deformation and acceleration for the SRM with solid shaft. (a) The directional deformation of mode-2; (b) the directional deformation of mode-5; (c) the directional acceleration of mode-2; (d) The directional acceleration of mode- 5 .

\section{Experimental Setup}

To validate this proposed study, the target experiment with a suitable approach was carried out. The measurement results were compared with the CFD results to verify the previous calculations. The water jacket with 17 channels of SRM prototype was manufactured, to confirm the CFD 
computation methods. Thermal testing involved inserting platinum resistance thermometer sensors (PT100) into the selected parts of the machine. The temperature rise of the stator and three ends winding were measured using five temperature sensors PT100. A PT100 sensor with an accuracy of type $\mathrm{A} \pm(0.15+0.002 T)$ was used. Figure 20 shows the positions of PT100 in the prototype SRM. The location of each PT100 sensor is described in Table 10. The five measuring points were connected to the temperature monitor for temperature recordings. An electric pump pushed the coolant through the water jacket. The flow meter was used to monitor the coolant flow rate of the inlet port, and the flow rate of water was adjusted to $0.6 \mathrm{~L} / \mathrm{s}$ at all times. The temperature rise of the outlet port was measured using an infrared radiation thermometer. The SRM was operated under a loaded condition at the rated speed of $105 \mathrm{rpm}$. Furthermore, the continuous output phase (DC) current rating of the power converter was $174 \mathrm{~A}$, and a DC bus voltage of $510 \mathrm{~V}$ was used to energize the SRM. The experimental platform for 72/48 SRM is developed and shown in Figure 21 [1]. The experimental platform of the Figure $21 \mathrm{~b}$ consists of:

(A) Three-Phase Power Quality Analyzer Fluke 434.

(B) Digital Oscilloscope (Measured Current).

(C) Digital Oscilloscope (Measured Voltage).

(D) Power Supply and Control System.

(E) $72 / 48$ Prototype SRM.

(F) The Load Disc is Connected Directly to SRM.

(G) Intelligent multi-channel Temperature inspection instrument (Temperature Monitor).

The load was carried by the disc, which was coupled to the SRM shaft and adjusted by dual brake calipers. Furthermore, by using a three-phase power quality analyzer (Fluke 434), a force sensor, an optical digital tachometer, and an oscilloscope with a Hall sensor, it was possible to monitor the SRM parameters, such as output power, load, current and speed, as shown in Figure 21b.

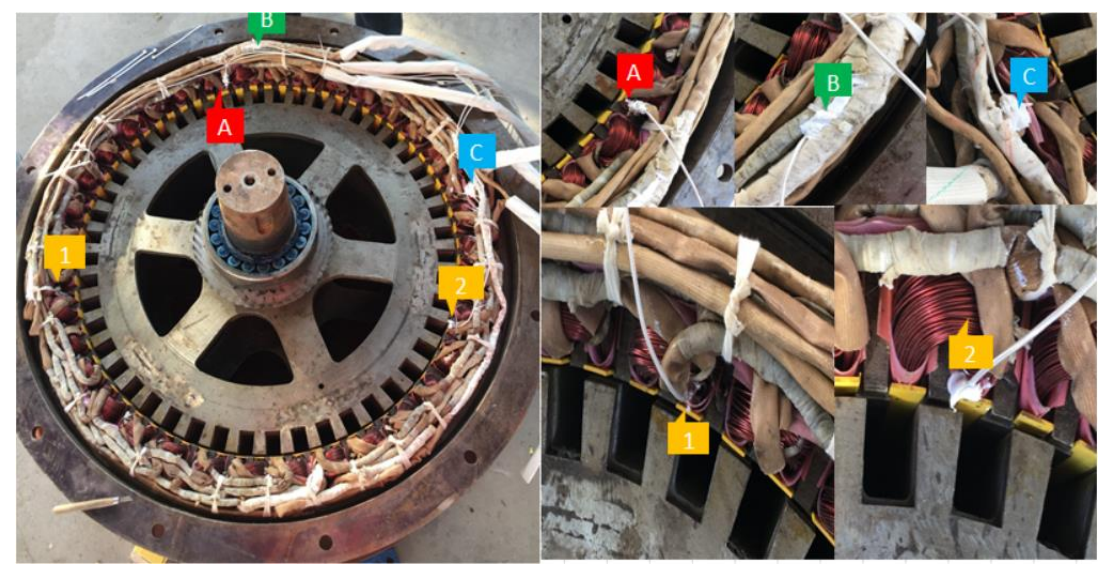

Figure 20. Positions of the PT100 in the prototype SRM.

Table 10. Description of PT 100 sensor locations in the prototype SRM.

\begin{tabular}{cc}
\hline PT100 & Location \\
\hline A & End Winding Phase A \\
B & End Winding Phase B \\
C & End Winding Phase C \\
1 & Stator Tooth Middle \\
1 & Stator Tooth Tope \\
\hline
\end{tabular}




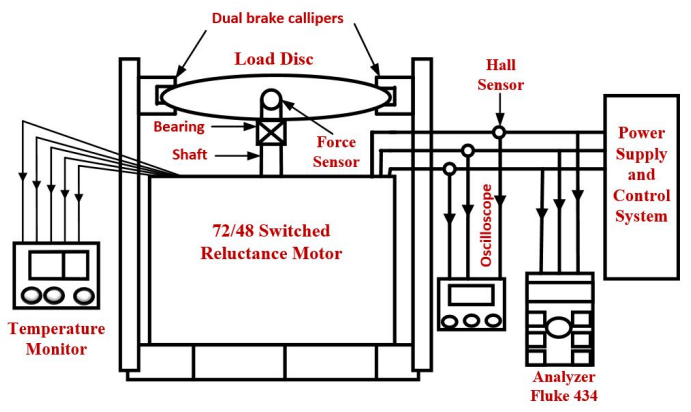

(a)

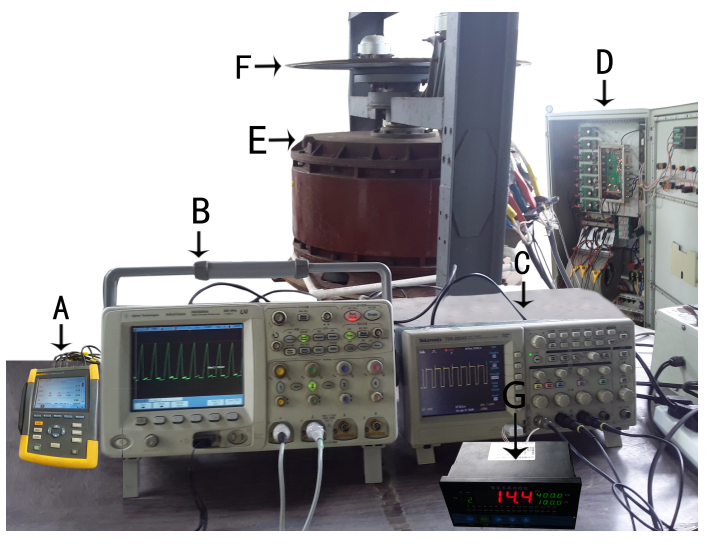

(b)

Figure 21. The experimental platform for the SRM system. (a) the diagram of the 72/48 SRM test bench; (b) the picture of the SRM test bench.

The ambient temperature was $26{ }^{\circ} \mathrm{C}$ during the experiment. The temperatures of five measuring points were recorded every $5 \mathrm{~min}$ using a temperature monitor until it reached a steady state. The temperature curves for various motor parts, underrated operating, are shown in Figure 22. The temperature of the components inside the motor was stable after $55 \mathrm{~min}$. The temperature of the sensor measured points is listed in Table 11, and CFD values were compared. From the data in Table 11, it is clear that the simulation temperatures results are in close agreement with the experimental results and the accuracy of the simulation results is proven. Measurement records show that the highest temperature of the SRM winding ends was $78^{\circ} \mathrm{C}$. Compared with the simulation results of $77.5^{\circ} \mathrm{C}$, the temperature difference was $0.5^{\circ} \mathrm{C}$, so the simulation results were credible.

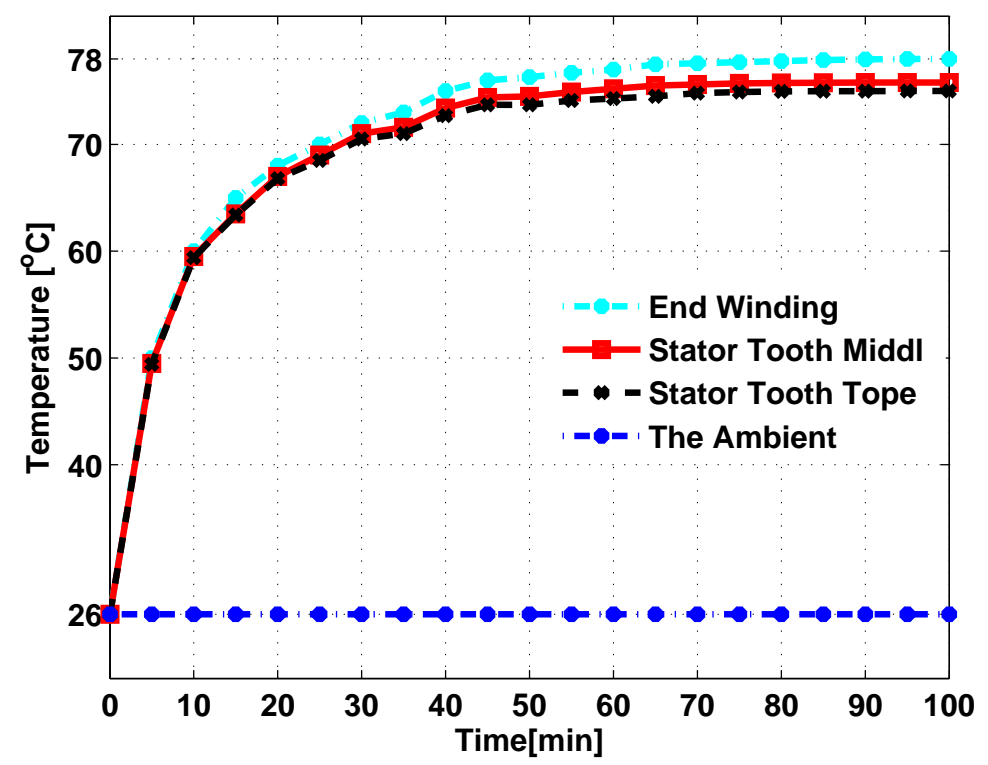

Figure 22. The experimental results of the temperature rising of the selected parts of the SRM.

Table 11. The measurement and CFD temperatures at steady-state of the SRM.

\begin{tabular}{cccccc}
\hline Portion of Sensor & A & B & C & $\mathbf{1}$ & $\mathbf{2}$ \\
\hline Experiment data $\left[{ }^{\circ} \mathrm{C}\right]$ & 78 & 78 & 78 & 75.8 & 75 \\
CFD of Figures $8 \mathrm{~d}$ and $9 \mathrm{~d}\left[{ }^{\circ} \mathrm{C}\right]$ & 77.5 & 77.5 & 77.5 & 75.4 & 74.7 \\
\hline
\end{tabular}

The measurement of the natural frequencies was done by a hammer impact test. Figure 23 shows the diagram of the 72/48 SRM test bench for the impulse hammer excitation. The experiments used an 
impact hammer (PCB 086C01) combination with the accelerometers. The first six natural frequencies of the SRM are shown in Table 12, and FEM values are compared. Of all the errors in the simulation, the natural frequencies are within $4 \%$. The errors may be due to the measurement instrument and the complexity of the prototype structure. The accuracy of the FEM is verified by experimental test.

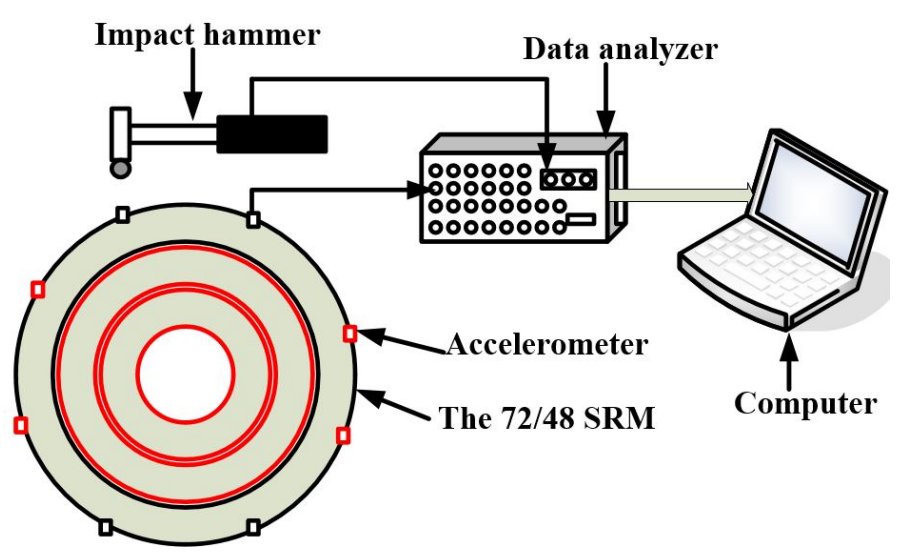

Figure 23. The diagram of impact hammer test bench for the SRM.

Table 12. Comparison of the FEM and experimental natural frequencies of the SRM with spoke shaft.

\begin{tabular}{cccc}
\hline Mode Shape & $\begin{array}{l}\text { Experimental } \\
\text { Modes (Hz) }\end{array}$ & $\begin{array}{l}\text { FEM Modes } \\
\text { of Spoke Shaft (Hz) }\end{array}$ & $\begin{array}{l}\text { Error } \\
\mathbf{( \% )}\end{array}$ \\
\hline M-1 & 490.3 & 508.64 & 3.7 \\
M-2 & 501.4 & 516.56 & 3.02 \\
M-3 & 729.7 & 748.64 & 2.59 \\
M-4 & 780.5 & 800.23 & 2.52 \\
M-5 & 842.2 & 859.18 & 2.02 \\
M-6 & 848.1 & 872.78 & 2.91 \\
\hline
\end{tabular}

\section{Conclusions}

A thermal and mechanical analysis of the switched reluctance motor (SRM) for mining applications was discussed in this paper. Several case studies of water jacket configurations were carried out to determine an appropriate method for ensuring uniform temperature distribution in the proposed model. A 2D finite element model for the SRM was developed to obtain the losses and radial force. The cooling jacket configurations with 17 channels at a flow rate of $0.6 \mathrm{~L} / \mathrm{s}$ were found to be optimal for a $75 \mathrm{~kW}, 72 / 48 \mathrm{SRM}$. The simulation results showed that the highest temperature point was $77.5^{\circ} \mathrm{C}$, located inside the SRM stator winding ends. The natural frequencies were calculated with the developed finite element mechanical, structural model. The 3D geometry of the SRM was modeled to obtain the vibration characteristics of the motor under free vibration for modal analysis, as well as the forced vibration response as radial forces for harmonic analysis. The structure of the shaft with a spoke was proposed for a $72 / 48$ SRM; the advantages of the structure caused the natural frequency to rise and reduced the weight and temperature of the SRM prototype. The experimental and computational fluid dynamics (CFD) results were compared and analyzed. The simulation results were in close agreement with the experimental results and the accuracy of the simulation results was proved.

Author Contributions: Conceptualization, E.E., Z.L. and G.L. Methodology, E.E. and Z.L.; Software, E.E.; Validation, E.E. and Z.L.; Formal analysis, E.E. and Z.L.; Investigation, Z.L. and E.E.; Resources, E.E. and Z.L.; Data curation, E.E. and Z.L.; Writing-original draft preparation, E.E.; Writing-review and editing, G.L. and Z.L.; Supervision, G.L. and Z.L.; Project administration, G.L.; Funding acquisition, G.L.

Funding: This research received no external funding.

Conflicts of Interest: The authors declare no conflict of interest. 


\section{References}

1. Elhomdy, E.; Li, G.; Liu, J.; Bukhari, S.; Cao, W. Design and Experimental Verification of a $72 / 48$ Switched Reluctance Motor for Low-Speed Direct-Drive Mining Applications. Energies 2018, 11, 192. [CrossRef]

2. Zhang, B.; Qu, R.; Fan, X.; Jin, W. Thermal and mechanical optimization of water jacket of permanent magnet synchronous machines for EV application. In Proceedings of the 2015 IEEE International Electric Machines and Drives Conference (IEMDC), Coeur d'Alene, ID, USA, 10-13 May 2015; pp. 1329-1335.

3. Uharek, S.; Baratchi, S.; Jiu, Y.; Majed, A.; Mitchell, A.; Rebner, K.; Karnutsch, C.; Khoshmanesh, K. Water jacket systems for temperature control of Petri dish cell culture chambers. Appl. Sci. 2019, 9, 621. [CrossRef]

4. Jebaseeli, E.; Paramasivam, S. Prediction of thermal behaviour of Switched Reluctance Machine using regression technique. In Proceedings of the 2015 IEEE International Conference on Electrical, Computer and Communication Technologies (ICECCT), Coimbatore, Tamilnadu, India, 5-7 March 2015; pp. 1-5.

5. Rehman, Z.; Seong, K. Three-D Numerical Thermal Analysis of Electric Motor with Cooling Jacket. Energies 2018, 11, 92. [CrossRef]

6. Boglietti, A.; Cavagnino, A.; Staton, D.; Shanel, M.; Mueller, M.; Mejuto, C. Evolution and Modern Approaches for Thermal Analysis of Electrical Machines. IEEE Trans. Ind. Electron. 2009, 56, 871-882. [CrossRef]

7. Nategh, S.; Krings, A.; Zhe, H.; Wallmark, O.; Lindenmo, M. Evaluation of stator and rotor lamination materials for thermal management of a PMaSRM. In Proceedings of the 2012 XXth International Conference on Electrical Machines, Marseille, France, 2-5 September 2012; pp. 1309-1314.

8. Chiu, H.; Jang, J.; Yan, W.; Shiao, R. Thermal performance analysis of a $30 \mathrm{~kW}$ switched reluctance motor. Int. J. Heat Mass Transf. 2017, 114, 145-154. [CrossRef]

9. Hu, Y.; Ding, W.; Wang, T.; Li, S.; Yang, S.; Yin, Z. Investigation on a Multi-Mode Switched Reluctance Motor: Design, Optimization, Electromagnetic Analysis and Experiment. IEEE Trans. Ind. Electron. 2017, 64, 9886-9895. [CrossRef]

10. Huang, Y.; Zhu, Z.; Guo, B.; Lin, H.; Fang, S. Design and thermal analysis on high torque low speed fractional-slot concentrated windings in-wheel traction motor. In Proceedings of the 2016 XXII International Conference on Electrical Machines (ICEM), Lausanne, Switzerland, 4-7 September 2016; pp. 1487-1492.

11. Udhav, U.; Ashok, B.; Eshan, D.; Shahjahan, A.; Narayanan, G.; Pramod, K. Thermal and mechanical design considerations for a switched reluctance motor. In Proceedings of the 2016 th India International Conference on Power Electronics (IICPE), Patiala, India, 17-19 November 2016; pp. 1-6.

12. Li, S.; Zhang, S.; Habetler, T.G.; Harley, R.G. A survey of electromagnetic Thermal modeling and design optimization of switched reluctance machines. In Proceedings of the 2017 IEEE International Electric Machines and Drives Conference (IEMDC), Miami, FL, USA, 21-24 May 2017; pp. 1-7.

13. Kasprzak, M.; Jiang, J.W.; Bilgin, B.; Emadi, A. Thermal analysis of a three-phase 24/16 switched reluctance machine used in HEVs. In Proceedings of the 2016 IEEE Energy Conversion Congress and Exposition (ECCE), Milwaukee, WI, USA, 18-22 September 2016; pp. 1-7.

14. Faiz, J.; Ganji, B.; Carstensen, C.; De Doncker, R. Loss prediction in switched reluctance motors using finite element method. Eur. Trans. Electr. Power 2009, 19, 731-748. [CrossRef]

15. Srinivas, N.; Arumugam, R. Analysis and characterization of switched reluctance motors: Part II Flow, thermal, and vibration analyses. IEEE Trans. Magn. 2005, 41, 1321-1332. [CrossRef]

16. Tiberiu, R.; Adrian, P.; Lorand, S. Noise Harshness and Vibration Characterization of Switched Reluctance Motors. J. Comp. Sci. Cont. Syst. 2016, 9, 34.

17. Gieras, J.; Wang, C.; Lai, C. Noise of Polyphase Electric Motors; CRC Press: Boca Raton, FL, USA, December 2005; ISBN 9780824723811.

18. $\mathrm{Ru}, \mathrm{L}$. Comparison of vibration between an evaporative cooling switched reluctance motor and a conventional switched reluctance motor. In Proceedings of the 2018 21st International Conference on Electrical Machines and Systems (ICEMS), Jeju, Korea, 7-10 October 2018; pp. 2483-2486.

19. Prabhu, S.; Chandrasekar, V.; Karthikeyan, P.; Lenin, N.C.; Arumugam, R. Vibration and thermal analysis of switched reluctance hub motor. Eur. J. Sci. Res. 2012, 68, 12-20.

20. Ebrahimi, Y.; Feyzi, R. Lumped Parameter Thermal Model for Axial Flux Switched Reluctance Motors. Electr. Power Compos. Syst. 2018, 45, 1-9. [CrossRef] 
21. Jebaseeli, E.; Paramasivam, S. Steady state and transient thermal analysis of switched reluctance machine. Int. J. Comput. Electr. Eng. 2012, 4, 794. [CrossRef]

22. Siadatan, A.; Mirimani, S.; Shamei, M.; Khalili, T. Thermal stability analysis of $6 / 4$ switch reluctance motor using finite element method. In Proceedings of the 2016 International Symposium on Power Electronics, Electrical Drives, Automation and Motion (SPEEDAM), Anacapri, Italy, 22-24 June 2016; pp. 382-387.

23. Chong, Y.C. Thermal Analysis and Air Flow Modelling of Electrical Machines. Ph.D. Thesis, University of Edinburgh, Edinburgh, UK, 2015.

24. Wang, S.W.; Zhang, Y.; Hu, J. Thermal Analysis of Water-Cooled Permanent Magnet Synchronous Motor for Electric Vehicles. Appl. Mech. Mater. 2014, 610, 129-135. [CrossRef]

25. Ying, X.; Jinpeng, G.; Peng, C.; Zhiwei, L. Coupled Fluid-Thermal Analysis for Induction Motors with Broken Bars Operating under the Rated Load. Energies 2018, 11, 2024.

26. Pillay, P.; Cai, W. An investigation into vibration in switched reluctance motors. IEEE Trans. Ind. Appl. 1999, 35, 589-596. [CrossRef]

27. Lecointe, J.; Romary, R.; Brudny, J.; Czapla, T. Five methods of stator natural frequency determination: case of induction and switched reluctance machines. Mech. Syst. Signal Proc. 2004, 18, 1133-1159. [CrossRef]

28. Senousy, M.; Larsen, P.; Ding, P. Electromagnetics, Structural Harmonics and Acoustics Coupled Simulation on the Stator of an Electric Motor. Int. J. Passeng. Cars Mech. Syst. 2014, 18, 822-828. [CrossRef]

29. Krishnan, R. Switched Reluctance Motor Drives: Modeling, Simulation, Analysis, Design, and Applications; CRC Press: Boca Raton, FL, USA, 2001; ISBN 0849308380.

30. Torrent, M.; Andrada, P.; Blanque, B.; Martinez, E.; Perat, J.; Sanchez, J. Method for estimating core losses in switched reluctance motors. Eur. Trans. Electr. Power 2013, 21, 757-771. [CrossRef]

31. Pyrhonen, J.; Jokinen, T.; Hrabovcova, V. Design of Rotating Electrical Machines; John Wiley \& Sons: New York, NY, USA, 2013; ISBN 978-1-118-58157-5.

32. Boglietti, A.; Cavagnino, A.; Staton, D. Determination of Critical Parameters in Electrical Machine Thermal Models. IEEE Trans. Ind. Appl. 2008, 44, 1150-1159. [CrossRef]

33. Kays, W.; Crawford, E.; Weigand, B. Convective Heat and Mass Transfer; McGraw-Hill Science/Engineering/ Math: New York, NY, USA, 2005; ISBN 100072990732.

34. Romanazzi, P.; Howey, A. Air gap convection in a switched reluctance machine. In Proceedings of the 2015 Tenth International Conference on Ecological Vehicles and Renewable Energies (EVER), Monte-Carlo, Monaco, France, 31 March-2 April 2015; pp. 1-7.

35. Hosain, M.; Fdhila, R.; Rönnberg, K. Air-gap Flow and Thermal Analysis of Rotating Machines using CFD. Energy Procedia 2017, 105, 5153-5159. [CrossRef]

36. Cuiping, L.; Yulong, P.; Ronggang, N.; Shukang, C. Analysis of 3D static temperature field of water cooling induction motor in mini electric vehicle. In Proceedings of the 2011 International Conference on Electrical Machines and Systems, Beijing, China, 20-23 August 2011; pp. 1-5.

37. Bergman, T.; Incropera, F.; Lavine, A.; DeWitt, D. Introduction to Heat Transfer; John Wiley \& Sons: Hoboken, NJ, USA, 2011; ISBN 100470917865

38. White, F.; Corfield, I. Viscous Fluid Flow; McGraw-Hill: New York, NY, USA, 2006; ISBN 100072402318.

39. Park, C.-B. Thermal analysis of IPMSM with water cooling jacket for railway vehicles. J. Electr. Eng. Technol. 2014, 9, 882-887. [CrossRef]

40. Chen, E.; Rupertus, G. Development of water jacket cooled motor and its applications in cement industry. In Proceedings of the 2017 IEEE-IAS/PCA Cement Industry Technical Conference, Calgary, AB, Canada, 21-25 May 2017; pp. 1-18.

41. Zhang, H.; Gao, C.; Wang, S. Analysis of radial force for switched reluctance motor. In Proceedings of the 2013 IEEE International Conference on Applied Superconductivity and Electromagnetic Devices, Beijing, China, 25-27 October 2013; pp. 418-419.

(C) 2018 by the authors. Licensee MDPI, Basel, Switzerland. This article is an open access article distributed under the terms and conditions of the Creative Commons Attribution (CC BY) license (http:/ / creativecommons.org/licenses/by/4.0/). 